OPEN ACCESS

Edited by:

Raquel Esteban,

University of the Basque Country,

Spain

Reviewed by:

Rudra Deo Tripathi,

National Botanical Research Institute

(CSIR), India

Zhenzhu Xu

Institute of Botany (CAS), China

*Correspondence:

Kamlesh K. Meena

kkmeenamicro@gmail.com

†These authors have combined first authors.

Specialty section:

This article was submitted to Functional Plant Ecology,

a section of the journal

Frontiers in Plant Science

Received: 07 September 2016 Accepted: 27 January 2017

Published: 09 February 2017

Citation:

Meena KK, Sorty AM, Bitla UM, Choudhary K, Gupta P, Pareek A,

Singh DP, Prabha R, Sahu PK, Gupta VK, Singh HB, Krishanani KK and Minhas PS (2017) Abiotic Stress

Responses and Microbe-Mediated Mitigation in Plants: The Omics

Strategies. Front. Plant Sci. 8:172. doi: $10.3389 / f p / s .2017 .00172$

\section{Abiotic Stress Responses and Microbe-Mediated Mitigation in Plants: The Omics Strategies}

\author{
Kamlesh K. Meena ${ }^{1 \times t}$, Ajay M. Sorty ${ }^{1+}$, Utkarsh M. Bitla', Khushboo Choudhary', \\ Priyanka Gupta2, Ashwani Pareek2, Dhananjaya P. Singh ${ }^{3}$, Ratna Prabha ${ }^{3}$, \\ Pramod K. Sahu ${ }^{3}$, Vijai K. Gupta ${ }^{4,5}$, Harikesh B. Singh ${ }^{6}$, Kishor K. Krishanani ${ }^{1}$ and \\ Paramjit S. Minhas ${ }^{1}$
}

\begin{abstract}
${ }^{1}$ Department of Microbiology, School of Edaphic Stress Management, National Institute of Abiotic Stress Management, Indian Council of Agricultural Research, Baramati, India, ${ }^{2}$ Stress Physiology and Molecular Biology Laboratory, School of Life Sciences, Jawaharlal Nehru University, New Delhi, India, ${ }^{3}$ Department of Biotechnology, National Bureau of Agriculturally Important Microorganisms, Indian Council of Agricultural Research, Kushmaur, India, ${ }^{4}$ Molecular Glyco-Biotechnology Group, Discipline of Biochemistry, School of Natural Sciences, National University of Ireland Galway, Galway, Ireland, ${ }^{5}$ Department of Chemistry and Biotechnology, ERA Chair of Green Chemistry, School of Science, Tallinn University of Technology, Tallinn, Estonia, ${ }^{6}$ Department of Mycology and Plant Pathology, Institute of Agricultural Sciences, Banaras Hindu University, Varanasi, India
\end{abstract}

Abiotic stresses are the foremost limiting factors for agricultural productivity. Crop plants need to cope up adverse external pressure created by environmental and edaphic conditions with their intrinsic biological mechanisms, failing which their growth, development, and productivity suffer. Microorganisms, the most natural inhabitants of diverse environments exhibit enormous metabolic capabilities to mitigate abiotic stresses. Since microbial interactions with plants are an integral part of the living ecosystem, they are believed to be the natural partners that modulate local and systemic mechanisms in plants to offer defense under adverse external conditions. Plantmicrobe interactions comprise complex mechanisms within the plant cellular system. Biochemical, molecular and physiological studies are paving the way in understanding the complex but integrated cellular processes. Under the continuous pressure of increasing climatic alterations, it now becomes more imperative to define and interpret plant-microbe relationships in terms of protection against abiotic stresses. At the same time, it also becomes essential to generate deeper insights into the stress-mitigating mechanisms in crop plants for their translation in higher productivity. Multi-omics approaches comprising genomics, transcriptomics, proteomics, metabolomics and phenomics integrate studies on the interaction of plants with microbes and their external environment and generate multi-layered information that can answer what is happening in real-time within the cells. Integration, analysis and decipherization of the big-data can lead to a massive outcome that has significant chance for implementation in the fields. This review summarizes abiotic stresses responses in plants in-terms of biochemical and molecular mechanisms followed by the microbe-mediated stress mitigation phenomenon. We describe the role of multi-omics approaches in generating multi-pronged information to provide a better understanding of 
plant-microbe interactions that modulate cellular mechanisms in plants under extreme external conditions and help to optimize abiotic stresses. Vigilant amalgamation of these high-throughput approaches supports a higher level of knowledge generation about root-level mechanisms involved in the alleviation of abiotic stresses in organisms.

Keywords: abiotic stress, genomics, metabolomics, microbes, multi-omics, plant-microbe interactions

\section{INTRODUCTION}

Adverse climatic conditions creating abiotic stresses are among the principal limiting factors for decline in agricultural productivity (Padgham, 2009; Grayson, 2013). As per the FAO report (2007), only $3.5 \%$ of the global land area has left unaffected by any environmental constraint ${ }^{1}$. Dominant abiotic stresses comprise drought, low/high temperature, salinity and acidic conditions, light intensity, submergence, anaerobiosis and nutrient starvation (Wang et al., 2003; Chaves and Oliveira, 2004; Agarwal and Grover, 2006; Nakashima and YamaguchiShinozaki, 2006; Hirel et al., 2007; Bailey-Serres and Voesenek, 2008). Water deficit (drought) has affected $64 \%$ of the global land area, flood (anoxia) 13\% of the land area, salinity 6\%, mineral deficiency 9\%, acidic soils $15 \%$ and, cold 57\% (Mittler, 2006; Cramer et al., 2011). Out of the world's 5.2 billion ha of dryland agriculture, 3.6 billion ha is affected by the problems of erosion, soil degradation and salinity (Riadh et al., 2010). Ruan et al. (2010) estimated salt affected soils to impact upon $50 \%$ of total irrigated land in the world costing US\$12 billion in terms of loss (Flowers et al., 2010). Similarly, global annual cost of land degradation by salinity in irrigated lands could be US\$ 27.3 billion due to loss in crop production (Qadir et al., 2014). The detrimental effect of salinity on plant growth is well established. The area under ever-increasing salinization has almost reached 34 million irrigated hectares (FAO, 2012) ${ }^{2}$. Although any accurate estimation of agricultural loss (reduction of crop production and soil health) in terms of agro-ecological disturbances due to abiotic stresses could not be made, it is evident that such stresses affect large land areas and significantly impact qualitative and quantitative loss in crop production (Cramer et al., 2011).

Plants frequently cope up with the rapid fluctuations and adversity of environmental conditions because of their intrinsic metabolic capabilities (Simontacchi et al., 2015). Variations in the outside environment could put the plant metabolism out of homeostasis (Foyer and Noctor, 2005), and create necessity for the plant to harbor some advanced genetic and metabolic mechanisms within its cellular system (Apel and Hirt, 2004; Gill and Tuteja, 2010). Plants possess an array of protective mechanisms acquired during the course of evolution to combat adverse environmental situations (Yolcu et al., 2016). Such mechanisms cause metabolic re-programming in the cells (Heil and Bostock, 2002; Swarbrick et al., 2006; Shao et al., 2008; Bolton, 2009; Massad et al., 2012) to facilitate routine biophysico-chemical processes irrespective of the external situations

${ }^{1}$ http://www.fao.org/docrep/010/a1075e/a1075e00.htm

${ }^{2} \mathrm{http}: / /$ www.fao.org/docrep/meeting/024/md324e.pdf
(Mickelbart et al., 2015). Many times plants get facilitated in reducing the burden of environmental stresses with the support of the microbiome they inhabit (Turner et al., 2013a; Ngumbi and Kloepper, 2014).

Microbial life is the most fundamental and live system on the earth. Being important living component of the soils, they naturally become integral part of the crop production system as soon as a seed comes into the soil to start its life cycle. Microorganisms are important inhabitants of seeds also, and proliferate as the seeds grow in the soils to form symbiotic associations at the surface or endophytic interactions inside the roots, stems or leaves. Plant microbiome provides fundamental support to the plants in acquiring nutrients, resisting against diseases and tolerating abiotic stresses (Turner et al., 2013a). Microbial intrinsic metabolic and genetic capabilities make them suitable organisms to combat extreme conditions of the environment (Sessitsch et al., 2012; Singh et al., 2014). Their interactions with the plants evoke various kinds of local and systemic responses that improve metabolic capability of the plants to fight against abiotic stresses (Nguyen et al., 2016). A testament to the important attributes of the microbial interactions with plants is significant number of accumulating pieces of evidence that suggest in-depth mechanisms based on plant-microbe interactions that offer modulation of cellular, biochemical and molecular mechanisms connected with stress tolerance (Bakker et al., 2012; Onaga and Wydra, 2016). Growing interest in uncultured microbes, especially from the rhizosphere of the crop plants, depleted and degraded soils, soils with disturbed fertility status and endophytic communities that potentially represent 'obligate endophytes' inhabiting plant tissues deciphered multi-phasic functions associated with the stress tolerance in microbial communities. The advent of next-generation sequencing (NGS) facilities supported gradually increasing metagenomic work and consequently led to the accumulation of greater amount of data for functional characterization of microbial communities in the soils (Bulgarelli et al., 2012).

Work on plant-microbe interactions at biochemical, physiological and molecular levels established that microbial associations largely direct plant responses toward stresses (Farrar et al., 2014). For dissecting deeper interaction mechanisms and connecting the changes at molecular levels with the tolerance responses against stresses, biological data based on the multi-omics approaches were generated (Kissoudis et al., 2014). The data generation and analysis was supported by the advancements in the high-end instrumentation and computational integration which helped to decipher individual signal molecules, proteins, genes and gene cascades to connect 
them with the gene networks/pathways for their function description. Technological developments also facilitated understanding of gene editing systems, RNAi-mediated gene silencing, mutant technology, proteomic analysis and metabolite profiling to reveal voluminous molecular information that helped in improving our understanding of microbe-mediated mitigation strategies of abiotic stresses in plants (Yin et al., 2014; Luan et al., 2015). Multi-omics approaches have emerged as a holistic and integrated analytical strategies for the dissection of one of the most complex and dynamic living system of microbial interactions with plants and modulating the consequences developed in the plants to help them overcome stresses. In this review, we aim at summarizing the implications of abiotic stresses and plant responses generated thereafter in terms of biochemical and molecular mechanisms followed by the microbe-mediated stress mitigation processes. We further describe the role of multi-omics approaches in establishing understanding of plant-microbe interactions that help plants optimize abiotic stresses.

\section{HOW DO ABIOTIC STRESSES AFFECT PLANTS?}

Plants need light, water, carbon and mineral nutrients for their optimal growth, development and reproduction. Extreme conditions (below or above the optimal levels) limit plant growth and development. An unfavorable environment comprising extreme high or low of temperature, salinity and drought pose a complex set of stress conditions. Plants can sense and react to stresses in many ways that favor their sustenance (Crane et al., 2011; Ahmad et al., 2015; Jiang et al., 2016). They remember past exposure to abiotic stresses and even mechanisms to overcome them in such a way that responses to repeated stresses can be modified accordingly (Hilker et al., 2015). However, the underlying molecular mechanisms are primarily unknown. The most obvious effect of unfavorable conditions initially appear at the cellular levels after that, physiological symptoms are observable. Water stress adversely affects physiological status of plants including the photosynthetic capability (Xu and Zhou, 2006). Prolonged water stress decreases leaf water potential and stomatal opening, reduces leaf size, suppresses root growth, reduces seed number, size, and viability, delays flowering and fruiting and limits plant growth and productivity (Osakabe et al., 2014; Xu et al., 2016) (Figure 1). Therefore, plants have smartly evolved different mechanisms to minimize consumption of optimal water resources and manage their growth till they face adverse conditions (Osakabe et al., 2013). Exposure to low or high light intensities diminishes physiological process and adversely influences growth and development of plants. Excess light induces photooxidation that increases the production of highly reactive oxygen intermediates to manipulate biomolecules and enzymes (Figure 1). Under severe conditions, loss in plant productivity is observed ( $\mathrm{Li}$ et al., 2009). Both freezing (cold) injury and/or an increase in temperature are major cause of crop loss (Koini et al., 2009; Pareek et al., 2010). Various edaphic factors like acidity, salinity, and alkalinity of soils (Bromham et al., 2013; Bui, 2013), pollutant contamination and anthropogenic perturbations (Emamverdian et al., 2015) severely affect plant development and adversely influence crop production (Figure 1). Different levels of acidic conditions badly influence soil nutrients and limit their ease of availability due to which plants become nutrient deficient and lose their normal physiological pattern of growth and development (Rorison, 1986). Early exposure to salinity leads to ion toxicity within the cell followed by disruption of osmotic balance when stress prolonged for longer duration. Combined effect of these ionic as well as osmotic shocks result into altered plant growth and development (Munns and Tester, 2008). Tolerance to salinity stress needs to maintain or quickly adjust both osmotic and ionic homeostasis within the cells. For combating salinity, plants usually try to avoid high saline environments by keeping sensitive plant tissues away from the zone of high salinity or by exuding ions from roots or compartmentalize ions away from the cytoplasm of physiologically active cells (Silva et al., 2010). Plants under extreme cold conditions survive either through avoiding super cooling of tissue water or through freezing tolerance. Certain species of plants have developed an ability to tolerate super-cooling or freezing temperatures by increasing their anti-freezing response within a short photoperiod, a process called cold acclimation (Thomashow, 2010).

After sensing the stress stimuli, plants exhibit an immediate and effective response to initiate a complex stress-specific signaling cascade (Chinnusamy et al., 2004; Andreasson and Ellis, 2010). Synthesis of phytohormone like abcisic acid, jasmonic acid, salicylic acid and ethylene (Spoel and Dong, 2008; Qin et al., 2011; Todaka et al., 2012), accumulation of phenolic acids and flavonoids (Singh et al., 2011; Tiwari et al., 2011), elaboration of various antioxidants and osmolytes and activation of transcription factors (TFs), are initiated along with the expression of stress-specific genes to mount appropriate defense system (Koussevitzky et al., 2008; Atkinson et al., 2013; Prasch and Sonnewald, 2013). Though many of the mechanisms related to stress tolerance in plants are known, our knowledge regarding 'on-field response' of the plants to simultaneous exposure to multiple stresses is still in quite an infancy.

The most crucial aspect in mitigating stress in plants is to understand fine level molecular machinery and its networks operative under stress conditions. This includes elaborative elucidation of abundance of metabolic pathways and their regulatory genes in the plant varieties. Identification of multigenic traits involved in stress responses, exploration of linked markers for such genes, and investigation of the probabilities to pool out important genes through breeding programs is the current focus of stress mitigation strategies. Other strategies that have put forward for the alleviation of abiotic stresses in plants include the use of various biomolecules of plant and microbial origin. These approaches are opening new gateways for scientists to dig out novel methods to alleviate the abiotic stresses in field grown plants. 


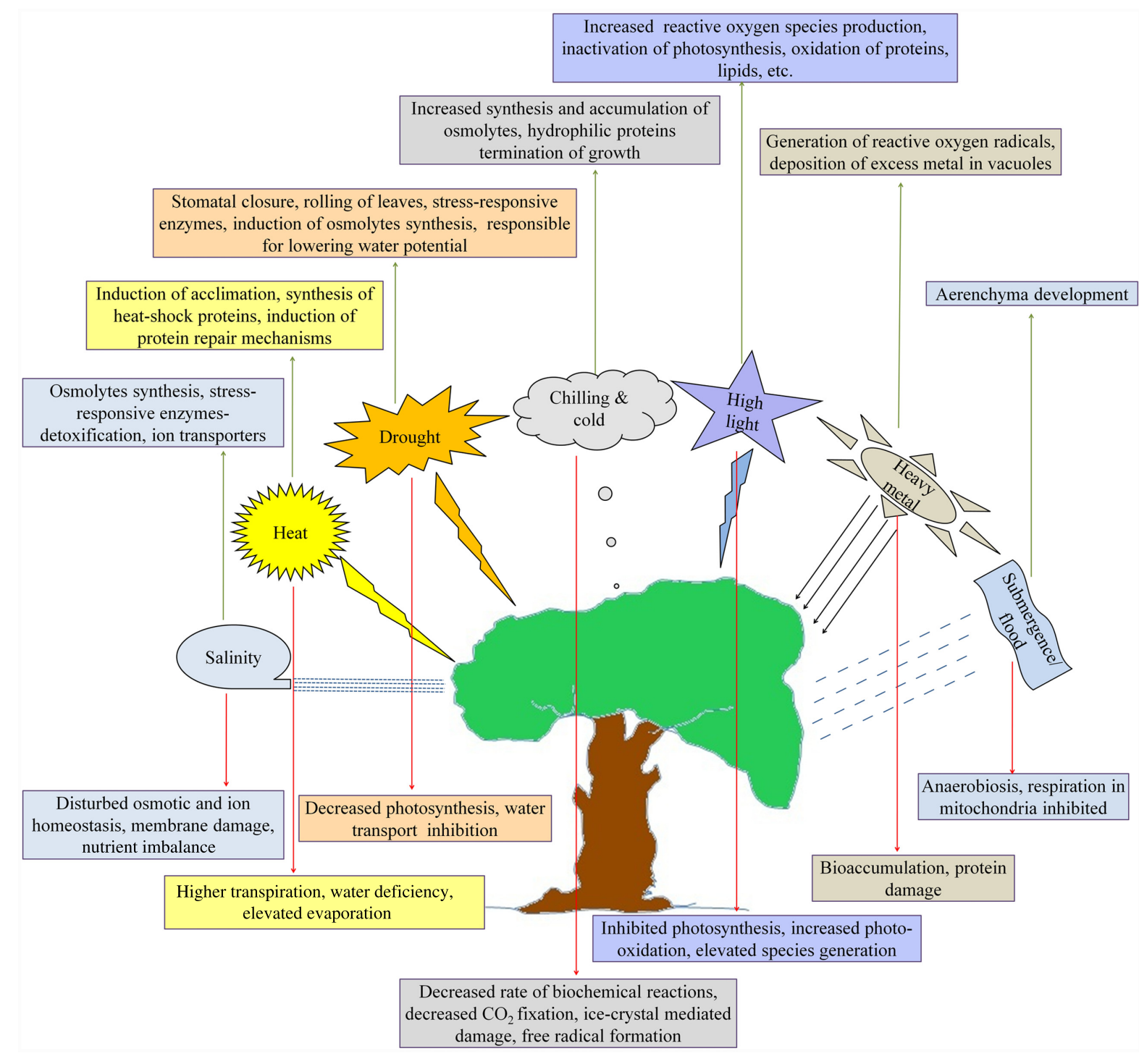

FIGURE 1 | Diverse abiotic stresses and the strategic defense mechanisms adopted by the plants. Though the consequences of heat, drought, salinity and chilling are different, the biochemical responses seem more or less similar. High light intensity and heavy metal toxicity also generate similar impact but submergence/flood situation leads to degenerative responses in plants where aerenchyma are developed to cope with anaerobiosis. It is therefore, clear that adaptive strategies of plants against variety of abiotic stresses are analogous in nature. It may provide an important key for mounting strategic tolerance to combined abiotic stresses in crop plants.

\section{PHYSIOLOGICAL AND MOLECULAR RESPONSES OF PLANTS AGAINST STRESSES}

Plants smartly sense, manage, maintain or escape changing environmental conditions (Figure 1). Their perception to environmental stimuli and responses to abiotic stresses involve an interactive metabolic crosstalk within diverse biosynthetic networks and pathways. Root architecture is thought to be more sensitive in sensing abiotic stimuli and reacting accordingly in the soils (Khan M.A. et al., 2016). It is a complex phenomenon that involves dynamic and real-time changes at genetic, transcriptomic, cellular, metabolic and physiological levels (Atkinson and Urwin, 2012). The foremost and direct impact of drought stress, frost, salinity and heat is creation of water deficient conditions within cells followed by a parallel development of biochemical, molecular and phenotypic responses against stresses (Cushman et al., 1990; Almoguera et al., 1995; Xu and Zhou, 2006). In the environment, the stresses experienced by the plants may be many, so as the complexity of their responses to multiple stresses in comparison to individual stress. The complexity lies in activating specific gene expression followed by metabolic programming in cells in response to individual stresses encountered. Tolerance, defense 
or susceptibility to stresses is a dynamic event involving multiple stages of plant's development. Rather than imposing an additive effect on plants, abiotic stress responses may reduce or enhance susceptibility of plants toward biotic stresses caused due to pests or pathogens (Rizhsky et al., 2004). This becomes more important when we take into account agricultural crops because, in many agricultural systems, most crops grow in suboptimal environmental conditions that are limiting to the genetic potential of the plants for growth and development (Bray et al., 2000). Defense, repair, acclimation and adaptation are the major components of resistance responses toward stresses.

Plants are vulnerable to water stress. Environmental changes like rewatering or cycled water conditions are created most frequently in the globally changing climatic conditions (Xu et al., 2010). Under severe water deficit conditions, peroxidation may be induced leading to negative impact on antioxidant metabolism (Bian and Jiang, 2009; Xu et al., 2014). Rewatering further decreases the level of peroxidation and restores growth and development of new plant parts and stomatal opening. In roots, both drought and rewatering lead to high accumulation of $\mathrm{H}_{2} \mathrm{O}_{2}$ (Bian and Jiang, 2009). Drought responses vary from plant to plant in terms of the activity of superoxide dismutase (SOD) enzyme that plays a central role in antioxidant metabolism (Xu Z. et al., 2015). In bluegrass, SOD activity remains unaffected by drought conditions and gene expression of FeSOD and $\mathrm{Cu} / \mathrm{ZnSOD}$ is down-regulated. In Alfalfa nodules, FeSOD and CU/ZnSOD are up-regulated by moderate drought, implicating that responses differ from species and tissues (Foyer and Noctor, 2005; Naya et al., 2007). An elevated level of salts present in the soil is detrimental to the plant cells, and different cells in a tissue respond differently to the stresses caused due to salinity (Voesenek and Pierik, 2008). Stressed cells irrespective of their location, whether at the root surface or within internal tissues, influence their neighbors and cause a change in their gene expression pattern over the stress duration (Dinneny et al., 2008). A drastic decrease in the osmotic potential of the soil occurs due to the elevated salt levels, the ultimate result of which is ion toxicity coupled with water stress in the plants. This situation can affect the vitality of the plants by suppressing seed germination and growth of the seedlings, hamper senescence of the plants and finally cause death (McCue and Hanson, 1990). The role of Salt Overly Sensitive (SOS) stress signaling pathway consisting of three majorly involved proteins SOS1, SOS2, and SOS3 is well demonstrated (Hasegawa et al., 2000). Salinity conditions cause decrease in the levels of aromatic amino acids like cysteine, arginine and methionine. Proline accumulation within the cells is a well-known alleviation strategy from salinity stress (Matysik et al., 2002). Similarly, generation of nitric oxide (NO), activation of antioxidant enzymes and compounds, modulation of hormones, accumulation of glycine betaine and polyols are some other changes within plants due to salinity stress (Gupta and Huang, 2014). This principally happens due to unavailability of water and mutilation in the nutrient availability caused due to high salt concentrations that create much damage to plant tissues and ultimately affect productivity.
Due to continued rise in global temperature, heat stress is becoming an important agricultural problem as it badly affects crop production. Rising temperature has an adverse impact on morpho-anatomical, physiological, biochemical and genetic changes in plants. A thorough understanding of physiological responses of plants to heat and mechanisms of tolerance could lead to strategic development of better approaches for crop production management (Wahid et al., 2007). Heat affects plants at different developmental levels, and high temperature causes reduced seed germination, loss in photosynthesis and respiration and decrease in membrane permeability (Xu et al., 2014). Alterations in the level of phytohormones, primary and secondary metabolites, enhancement in the expression of heat shock and related proteins and production of reactive oxygen species (ROS) are some prominent responses of plants against heat stress (Iba, 2002) (Figure 1). Mitigation strategies in plants against heat stress involve activation of mechanisms that support maintenance of membrane stability and induction of mitogen-activated protein kinase (MAPK) and calcium-dependent protein kinase (CDPK) cascades (Wang and Li, 2006). Besides, scavenging of ROS, accumulation of antioxidant metabolites and compatible solutes, chaperone signaling and transcriptional modulation are certain parallel activities that help cells to sustain heat stress (Wahid et al., 2007).

Multiple stress conditions impose more beneficial impacts on plants compared to that posed in presence of individual stress alone. Combination of stresses ultimately reduce the detrimental effect of each other thereby, increasing the probability of better survival of plants. Iyer et al. (2013) demonstrated that the cumulative impact of drought and accumulation of ozone $\left(\mathrm{O}_{3}\right)$ in plants resulted in better tolerance. The combined affect was attributed to decreased values of stomatal conductance. Elevated concentration of reduced glutathione and ascorbic acid effectively scavenge ROS, thereby causing a considerable drop in the total ROS content. However, it is a difficult task to infer response pattern of a plant against any single stress, particularly when it is growing in the field from the cumulative impact of environmental stresses. Multiple stresses occur simultaneously in field conditions and so, multifaceted mechanisms exist in the plants to cope-up with rapidly fluctuating adverse situations. Although much efforts have been made to assess plant responses toward single stress conditions (Rizhsky et al., 2002, 2004; Mittler, 2006; Mittler and Blumwald, 2010; Alameda et al., 2012; Atkinson and Urwin, 2012; Kasurinen et al., 2012; Srivastava et al., 2012; Perez-Lopez et al., 2013; Rivero et al., 2013), attempts to assess the impact of combined stress conditions on crop plants under simulated laboratory trials are limited. This particularly limits our knowledge and understanding of plant responses to combined stresses and prediction of cumulative stress tolerance mechanisms in laboratory or field conditions.

Phytohormones are crucial for the plant growth and development but they critically play role in the abiotic stress tolerance (Wani et al., 2016). Gene expression profiling revealed that prioritization of signals done by protein switches like kinases, TFs and G-proteins are mostly regulated by hormones 
(Depuyd and Hardtke, 2011; Yao et al., 2011). Plants typically channel their physiological resources toward adapting to abiotic stress which makes them more susceptible to biotic stresses like herbivory and disease attack (Zabala et al., 2009; Hey et al., 2010). ABA-dependent abiotic stress response pathways are predominant. Other defense pathways rooted through salicylic acid, jasmonic acid or ethylene also trigger plants for abiotic stress response. For example, triggering ROS production to minimize loss during abiotic stress may prevent plants from biotrophic pathogen attack, but it makes plants more prone for necrotrophic pathogens. The other hormone, JA is effective for defense responses to necrotrophic pathogens and associated to ISR by beneficial microbes (Matilla et al., 2010). Study of omics may help in understanding these complex plant-microbe interactions and harvesting associated and linked understanding.

\section{MICROBE-MEDIATED MITIGATION OF ABIOTIC STRESSES}

Microbial interactions with crop plants are key to the adaptation and survival of both the partners in any abiotic environment. Induced Systemic Tolerance (IST) is the term being used for microbe-mediated induction of abiotic stress responses. The role of microorganisms to alleviate abiotic stresses in plants has been the area of great concern in past few decades (de Zelicourt et al., 2013; Nadeem et al., 2014; Souza et al., 2015). Microbes with their potential intrinsic metabolic and genetic capabilities, contribute to alleviate abiotic stresses in the plants (Gopalakrishnan et al., 2015). The role of several rhizospheric occupants belonging to the genera Pseudomonas (Grichko and Glick, 2001; Ali et al., 2009; Sorty et al., 2016), Azotobacter (Sahoo et al., 2014a,b), Azospirillum (Creus et al., 2004; Omar et al., 2009), Rhizobium (Alami et al., 2000; Remans et al., 2008; Sorty et al., 2016), Pantoea (Amellal et al., 1998; Egamberdiyeva and Höflich, 2003; Sorty et al., 2016), Bacillus (Ashraf et al., 2004; Marulanda et al., 2007; Tiwari et al., 2011; Vardharajula et al., 2011; Sorty et al., 2016), Enterobacter (Grichko and Glick, 2001; Nadeem et al., 2007; Sorty et al., 2016), Bradyrhizobium (Fugyeuredi et al., 1999; Swaine et al., 2007; Panlada et al., 2013), Methylobacterium (Madhaiyan et al., 2007; Meena et al., 2012), Burkholderia (Barka et al., 2006; Oliveira et al., 2009), Trichoderma (Ahmad et al., 2015) and cyanobacteria (Singh et al., 2011) in plant growth promotion and mitigation of multiple kinds of abiotic stresses has been documented. Recently, Pandey et al. (2016) have demonstrated the role of Trichoderma harzianum on stress mitigation in rice genotypes due to upregulation of aquaporin, dehydrin and malonialdehyde genes along with various other physiological parameters. Rhizobacteria-induced drought endurance and resilience (RIDER) that includes changes in the levels of phytohormones, defense-related proteins and enzymes, antioxidants and epoxypolysaccharide have been observed for microbe-mediated plant responses. Such strategies make plants tougher toward abiotic stresses (Kaushal and Wani, 2016). The selection, screening and application of stresstolerant microorganisms, therefore, could be viable options to help overcome productivity limitations of crop plants in stress-prone areas. Enhanced oil content in $\mathrm{NaCl}$ affected Indian mustard (Brassica juncea) was reported by Trichoderma harzianum application which improved the uptake of essential nutrients, enhanced accumulation of antioxidants and osmolytes and decreased $\mathrm{Na}^{+}$uptake (Ahmad et al., 2015). Parallel to such reports, up-regulation of monodehydroascorbate reductase in Trichoderma treated plants was demonstrated. It was also confirmed by mutant studies that Trichoderma ameliorates salinity stress by producing ACC-deaminase (Brotman et al., 2013). In barley and oats, Pseudomonas sp. and Acinetobacter sp. were reported to enhance production of IAA and ACCdeaminase in salt affected soil (Chang et al., 2014). Palaniyandi et al. (2014) reported alleviation of salt stress and growth promotion by Streptomyces sp. strain PGPA39 in 'Micro-Tom' tomato plants. Burkholderia phytofirmans strain PsJN mitigates drought stress in maize (Naveed et al., 2014b), wheat (Naveed et al., 2014a) and salt stress in Arabidopsis (Pinedo et al., 2015).

The rhizosphere comprises the fraction of soil in vicinity of the plant roots. It constitutes a soil microenvironment in the proximity of root region where the average count of microorganisms is very high than rest of the bulk soil. It is, therefore, obvious that plant roots with a diversity of their nutrient, mineral and metabolite composition, could be a major factor responsible for attracting microorganisms to accumulate and associate alongside. The secretion of root exudates by plants is a vital factor for microbial colonization within the rhizosphere. Chemotactic movement of microorganisms toward the root exudates plays the role of dragging force for the microbial communities to colonize on the roots. While utilizing the rhizosphere-microenvironment around plant roots, the PGPRs may act as biofertilizers, phytostimulators or biocontrol agents depending upon their inherent capabilities, mode of interaction and competitive survival conditions. Growth promoting bacteria stimulate plant growth by employing several broadly categorized direct and indirect mechanisms (Braud et al., 2009; Hayat et al., 2010). Direct mechanisms include synthesis of bacterial compounds which facilitate uptake of essential nutrients and micronutrients from the soil along with the production of plant growth regulators, e.g., iron and zinc sequestration, siderophore production, phosphorus and potassium solubilisation, plant hormone production, and atmospheric nitrogen fixation. On the other hand, indirect mechanisms involve antagonistic activity toward plant pathogenic organisms, production of $\mathrm{HCN}$ and antifungal compounds and tolerance against abiotic stresses. Besides this, the bacteria can induce systemic resistance in plants by their metabolites acting as extracellular signals, which subsequently trigger a series of internal processes. Eventually, the translocated signal is perceived by the distant plant cells triggering the activation of the defense mechanism. Besides bacteria, fungi particularly the mycorrhiza are also important plant growth promoters. These are principally divided into mycorrhizal fungi and vesicular-arbuscular mycorrhizal (VAM) fungi. These fungi remain associated with the host plant externally (ectomycorrhizae) or they may form endosymbiotic associations (VAM). These fungi form extensive networking of very fine hyphae, thus increasing overall nutrient uptake by the roots. The root fungal endophyte Piriformospora indica 
induces salt tolerance in barley (Baltruschat et al., 2008) and drought tolerance in Chinese cabbage (Sun et al., 2010) by increasing the levels of antioxidants and improving many other aspects (Franken, 2012). The potential of microbial interactions with the plants have, therefore, multipronged role. At one end, microbes induce local or systemic stress alleviation response mechanisms in plants to sustain under abiotic stress conditions while at the other end, they help plants to maintain their growth and development through fixation, mobilization and/or production of nutrients, hormones and organic phytostimulant compounds. Such multifaceted action of microorganisms or their communities makes them strong, viable and vital options for abiotic stress mitigation strategies in crop plants.

Several mechanisms highlighting the role of microbes in abiotic stress alleviation have been proposed. Soil-inhabiting microbes belonging to genera Achromobacter, Azospirillum, Variovorax, Bacillus, Enterobacter, Azotobacter, Aeromonas, Klebsiella and Pseudomonas have been shown to enhance plant growth even under unfavorable environmental conditions (Pishchik et al., 2002; Hamdia et al., 2004; Mayak et al., 2004; Arkhipova et al., 2007; Barriuso et al., 2008a,b; Dardanelli et al., 2008; Belimov et al., 2009; Ortiz et al., 2015; Kaushal and Wani, 2016; Sorty et al., 2016). Literature relating to the involvement of microbes for the alleviation of abiotic stressors signifies the importance of microbes in this area (Table 1). All such soil bacteria that are capable of inducing plant growth under variety of physicochemical and environmental conditions are classified cumulatively as plant growth promoters (PGP). There exists different mechanisms by which microbes induce plant growth. The plant-growth regulating molecules predominantly, indole acetic acid (IAA) are synthesized in shoot and accumulated in the actively growing regions of roots. The IAA and other auxins have growth-stimulating effect in terms of cell elongation resulting in root growth initiation. Moreover, these molecules also promote the development of lateral roots. Higher concentrations of auxins, on the other hand, are known to have a negative impact on root growth (Jackson, 1991; Sorty et al., 2016). A similar situation can also happen due to increased synthesis of ethylene (Jackson, 1991). The rhizosphere colonizing bacteria were reported to perform in a similar manner, and produce phytohormones to enhance plant growth (Bowen and Rovira, 1991; Timmusk and Wagner, 1999; German et al., 2000; Belimov et al., 2007). Evidences from recent agricultural practices witness that the PGPRs not just help in mitigation of environmental stresses, but also improve yield of diverse crop plants including rice, maize, barley and soybean (Tapias et al., 2012; Sharma et al., 2013; Sen and Chandrasekhar, 2014; Suarez et al., 2015). A mechanism of salt tolerance imposed by Pseudomonas sp. PMDzncd2003 on rice germination under salinity stress is demonstrated. Better root colonizing capability of Pseudomonas sp. along with its ability to produce exopolysaccharides (EPS) leads to enhanced tolerance toward salinity (Sen and Chandrasekhar, 2014). Similarly, Khan A. et al. (2016) have shown that inoculation of Bacillus pumilus improved rice growth in response to salinity and high boron stresses. A possible mechanism was suggested, that higher expression of antioxidant enzyme machinery in the presence of bacterial inoculant may lead to cell protection in stress conditions. More efforts are now needed to dissect molecular mechanisms involved in the communication between plant and bacterial colonizers.

\section{MULTI-OMICS APPROACHES TO ADDRESS ALLEVIATION OF ABIOTIC STRESS}

The ecology of plant-microbe interaction is very complicated and interwoven system. It is important to understand the fine-tuning and integration of diverse signals generated by microbial interactions in the plants for advantage in crop improvement. A plant has to combat multiple biotic and abiotic stresses in the environment. Multiple stress factors produce complex defense signals in plants and therefore, the result of plant-microbe interaction can be decided by prioritization of physiological pathways in plants (Schenk et al., 2012). Interaction of microbes with plant roots evoke multipronged responses in local and/or in distal plant parts at physiological, biochemical and molecular level. Such responses at all levels have their interconnections with the stress; many are parallel to stress responses while others are adverse. For dissecting the mechanisms, multi-omics approaches can be applied to address the challenging task of deciphering changes in plants at genetic, proteomic or metabolomic level (Figure 2). Entwined with the advances in bioinformatics, the datadriven science of multi-omics has improved our knowledge in understanding the microbial community composition and their functional behavior in complex environments like rhizosphere, where inter-connections among microbial communities direct plant responses toward stresses. Recently, meta-omics approaches including metagenomics, metatranscriptomics and metaproteomics have emerged as promising tools to address microbial communities and functions within a given environment at a deeper level (de Castro et al., 2013).

\section{GENOMICS}

Abiotic stress alleviation by altering crop genetics is of paramount importance and is a challenging issue that requires extensive breeding programs (Grainger and Rajcan, 2013). Low heritability and environmental variations make such breeding programs even more challenging (Manavalan et al., 2009). Strategic markerassisted breeding is efficient in accelerating tolerance in cultivars. Understanding about genomic loci governing traits responsible for tolerance and availability of molecular markers tightly linked with it is a prerequisite for marker assisted selection (Xu et al., 2012). A large amount of genomic data in the form of sequenced genomes and expression profiles are thus, impetuous for breeding for stress alleviation (Sonah et al., 2011; Tomar et al., 2014). Use of genomics-based technologies has made a great impact in crop improvement programs. Use of molecular markers in crop improvement for the accumulation of silicon $(\mathrm{Si})$ in rice 
TABLE 1 | Microbe-mediated abiotic stress tolerance in plants.

\begin{tabular}{|c|c|c|c|c|}
\hline Abiotic stress & Microbe inoculation & Plant & Tolerance strategy & Reference \\
\hline Salt & Bacillus subtilis GB03 & Arabidopsis thaliana & $\begin{array}{l}\text { Tissue-specific regulation of sodium } \\
\text { transporter HKT1 }\end{array}$ & Zhang et al., 2008 \\
\hline Salt & Pseudomonas simiae & Glycine max & $\begin{array}{l}\text { 4-nitroguaiacol and quinoline promote } \\
\text { soybean seed germination }\end{array}$ & Vaishnav et al., 2016 \\
\hline Salt & $\begin{array}{l}\text { Pseudomonas syringae } \\
\text { DC3000, Bacillus sp. strain } \\
\text { L81, Arthrobacter oxidans }\end{array}$ & Arabidopsis thaliana & SA-dependent pathway & Barriuso et al., 2008b \\
\hline Salt & $\begin{array}{l}\text { Root-associated plant } \\
\text { growth-promoting rhizobacteria } \\
\text { (PGPR) }\end{array}$ & Oryza sativa & $\begin{array}{l}\text { Expression of salt stress-related } R A B 18 \\
\text { plant gene }\end{array}$ & Jha et al., 2014 \\
\hline Salt & $\begin{array}{l}\text { Cyanobacteria and } \\
\text { cyanobacterial extracts }\end{array}$ & $\begin{array}{l}\text { Oryza sativa, Triticum } \\
\text { aestivum, Zea mays, } \\
\text { Gossypium hirsutum }\end{array}$ & Phytohormones as elicitor molecule & Singh, 2014 \\
\hline Salt & $\begin{array}{l}\text { Pseudomonas koreensis strain } \\
\text { AK-1 }\end{array}$ & Glycine max L. Merrill & $\begin{array}{l}\text { Reduction in } \mathrm{Na}^{+} \text {level and increase in } \\
\mathrm{K}^{+} \text {level }\end{array}$ & Kasotia et al., 2015 \\
\hline Osmotic stress & Bacillus megaterium & Zea mays & $\begin{array}{l}\text { High hydraulic conductance, increased } \\
\text { root expression of two ZmPIP isoforms }\end{array}$ & Marulanda et al., 2010 \\
\hline Osmotic stress & Glomus intraradices BEG 123 & Phaseolus vulgaris & $\begin{array}{l}\text { High osmotic root hydraulic } \\
\text { conductance due to increased active } \\
\text { solute transport through roots }\end{array}$ & Aroca et al., 2007 \\
\hline Salt & Glomus etunicatum & Glycine max & $\begin{array}{l}\text { Increased root but decreased shoot } \\
\text { proline concentrations }\end{array}$ & Sharifi et al., 2007 \\
\hline Salt & $\begin{array}{l}\text { Burkholderia, Arthrobacter and } \\
\text { Bacillus }\end{array}$ & $\begin{array}{l}\text { Vitis vinifera, Capsicum } \\
\text { annuum }\end{array}$ & Increased accumulation of proline & Barka et al., 2006 \\
\hline Drought & $\begin{array}{l}\text { Rhizobium tropici and } \\
\text { Paenibacillus polymyxa } \\
\text { (Co-inoculation) }\end{array}$ & Phaseolus vulgaris & $\begin{array}{l}\text { Upregulation of genes involved in stress } \\
\text { tolerance }\end{array}$ & Figueiredo et al., 2008 \\
\hline Salt & Glomus fasciculatum & Phragmites australis & Accumulation of carbohydrates & Al-Garni, 2006 \\
\hline Salt & Glomus intraradices & Glycine max & Accumulation of carbohydrates & Porcel and Ruiz-Lozano, 2004 \\
\hline Salinity & $\begin{array}{l}\text { Azospirillum brasilense and } \\
\text { Pantoea dispersa } \\
\text { (Co-inoculation) }\end{array}$ & Capsicum annuum & $\begin{array}{l}\text { High stomatal conductance and } \\
\text { photosynthesis }\end{array}$ & $\begin{array}{l}\text { del Amor and Cuadra-Crespo } \\
\text { (2012) }\end{array}$ \\
\hline Salinity & $\begin{array}{l}\text { Glomus intraradices BAFC } \\
3108\end{array}$ & Lotus glaber & $\begin{array}{l}\text { Decreased root and shoot } \mathrm{Na}^{+} \\
\text {accumulation and enhanced root } \mathrm{K}^{+} \\
\text {concentrations }\end{array}$ & Sannazzaro et al., 2006 \\
\hline Salinity & $\begin{array}{l}\text { Glomus clarum } \\
\text { Glomus etunicatum }\end{array}$ & $\begin{array}{l}\text { Vigna radiata, } \\
\text { Capsicum annuum, } \\
\text { Triticum aestivum }\end{array}$ & $\begin{array}{l}\text { Decreased } \mathrm{Na}^{+} \text {in root and shoot and } \\
\text { incesaed concentration of } \mathrm{K}^{+} \text {in root }\end{array}$ & $\begin{array}{l}\text { Rabie, 2005; Daei et al., 2009; } \\
\text { Kaya et al., } 2009\end{array}$ \\
\hline Salinity & Bacillus subtilis & Arabidopsis & $\begin{array}{l}\text { Decreased root transcriptional } \\
\text { expression of a high-affinity } \mathrm{K}^{+} \\
\text {transporter (AtHKT1) decreasing root } \\
\mathrm{Na}^{+} \text {import }\end{array}$ & Zhang et al., 2008 \\
\hline Salinity & Glomus intraradices BEG121 & Lactuca sativa & Reduced concentration of ABA & Aroca et al. (2008) \\
\hline Salinity & Pseudomonas putida Rs-198 & Gossypium hirsutum & $\begin{array}{l}\text { Prevented salinity-induced ABA } \\
\text { accumulation in seedlings }\end{array}$ & Yao et al., 2010 \\
\hline Salinity & $\begin{array}{l}\text { Azospirillum brasilense strain } \\
\mathrm{Cd}\end{array}$ & Phaseolus vulgaris & $\begin{array}{l}\text { Stimulation of persistent exudation of } \\
\text { flavonoids }\end{array}$ & Dardanelli et al., 2008 \\
\hline Salinity & Bacillus subtilis & Lactuca sativa & $\begin{array}{l}\text { Root-to-shoot cytokinin signalling and } \\
\text { stimulation of shoot biomass }\end{array}$ & Arkhipova et al., 2007 \\
\hline Drought & $\begin{array}{l}\text { Burkholderia phytofirmans } \\
\text { Enterobacter sp. FD17 }\end{array}$ & Zea mays & $\begin{array}{l}\text { Increased photosynthesis, root and } \\
\text { shoot biomass under drought } \\
\text { conditions }\end{array}$ & Naveed et al., 2014b \\
\hline Drought & Bacillus thuringiensis AZP2 & Triticum aestivum & $\begin{array}{l}\text { Production of volatile organic } \\
\text { compounds }\end{array}$ & Timmusk et al., 2014 \\
\hline Drought & Pseudomonas chlororaphis O6 & Arabidopsis thaliana & $\begin{array}{l}\text { Production of } 2 \mathrm{R}, 3 \mathrm{R} \text { butanediol- a } \\
\text { volatile compound }\end{array}$ & Cho et al., 2008 \\
\hline Drought & $\begin{array}{l}\text { Pseudomonas putida strain } \\
\text { GAP-P45 }\end{array}$ & Helianthus annuus & Epoxypolysaccharide production & Sandhya et al., 2009 \\
\hline Drought & Bacillus licheformis strain K11 & Capsicum annum & Stress related genes and proteins & Lim and Kim, 2013 \\
\hline
\end{tabular}


TABLE 1 | Continued

\begin{tabular}{|c|c|c|c|c|}
\hline Abiotic stress & Microbe inoculation & Plant & Tolerance strategy & Reference \\
\hline Drought & $\begin{array}{l}\text { Bacillus cereus AR156, } \\
\text { B. subtilis SM21 and Serratia } \\
\text { sp. XY21 }\end{array}$ & Cucumis sativa & $\begin{array}{l}\text { Production of monodehydro ascorbate, } \\
\text { proline, and antioxidant enzyme, } \\
\text { expression of genes }\end{array}$ & Wang et al., 2012 \\
\hline Heat & $\begin{array}{l}\text { Bacillus amyloliquefaciens, } \\
\text { Azospirillum brasilence }\end{array}$ & Triticum aestivum & $\begin{array}{l}\text { Reduced regeneration of reactive } \\
\text { oxygen species, preactivation of heat } \\
\text { shock transcription factors, changes in } \\
\text { metabolome }\end{array}$ & El-Daim et al., 2014 \\
\hline Heat and drought & $\begin{array}{l}\text { Curvularia proturberata isolate } \\
\text { Cp4666D }\end{array}$ & $\begin{array}{l}\text { Dichanthelium } \\
\text { lanuginosum, Solanum } \\
\text { lycopersicum }\end{array}$ & Colonization of roots & de Zelicourt et al., 2013 \\
\hline Arsenic toxicity & Staphylococcus arlettae & Brassica juncea & $\begin{array}{l}\text { Increased soil dehydrogenase, } \\
\text { phosphatase and available phosphorus }\end{array}$ & Srivastava et al., 2013 \\
\hline $\mathrm{Pb} / \mathrm{Zn}$ toxicity & $\begin{array}{l}\text { Phyllobacterium } \\
\text { myrsinacearum }\end{array}$ & Sedum plumbizincicola & $\begin{array}{l}\text { Resistance to 350mg/L Cd, } 1000 \mathrm{mg} / \mathrm{L} \\
\mathrm{Zn}, 1200 \mathrm{mg} / \mathrm{L} \mathrm{Pb}\end{array}$ & Ma et al., 2013 \\
\hline Zn toxicity & Pseudomonas aeruginosa & Triticum aestivum & $\begin{array}{l}\text { Improved biomass, } \mathrm{N} \text { and } \mathrm{P} \text { uptake } \\
\text { and total soluble protein }\end{array}$ & Islam et al., 2014 \\
\hline Zn toxicity & $\begin{array}{l}\text { Enterobacter intermedius } \\
\mathrm{MH} 8 \mathrm{~b}\end{array}$ & Sinapis alba & $\begin{array}{l}\text { ACC deaminase, IAA, hydrocyanic acid, } \\
\text { P solubilization }\end{array}$ & Plociniczak et al., 2013 \\
\hline $\begin{array}{l}\mathrm{Cd}, \mathrm{AS}, \mathrm{Cu}, \mathrm{Pb} \text { and } \\
\text { Zn toxicity }\end{array}$ & $\begin{array}{l}\text { Pseudomonas koreensis } \\
\text { AGB-1 }\end{array}$ & Miscanthus sinensis & ACC deaminase, IAA production & Babu et al., 2015 \\
\hline Zn toxicity & $\begin{array}{l}\text { Pseudomonas brassicacearum, } \\
\text { Rhizobium leguminosarum }\end{array}$ & Brassica juncea & Metal-chellating molecules & Adediran et al., 2016 \\
\hline Hg toxicity & Photobacterium spp. & Phragmites australis & IAA, mercury reductase activity & Mathew et al., 2015 \\
\hline
\end{tabular}

to enhance the tolerance of plant for abiotic stress is in vogue. Ma et al. (2004) used PCR-based markers for microsatellite (RM5303) and expressed sequence tag (EST, E60168) in mapping Si transporter gene during a bulk segregant experiments.

Besides crop breeding programs, a significant level of abiotic stress alleviation in plants can be achieved through the manifestations of plant-microbe interaction also. Omics approaches help to have deep insight into the mechanisms of established plant-microbe interactions (Figure 2). In a study of Trichoderma-plant interaction (T. atroviride and T. harzianum with tomato), Tucci et al. (2011) reported the impact of genotypic characteristics of plants for modulation of microbeplant interaction leading to its effect on plant growth and stress alleviation. Growth promoting and stress alleviating activity of $T$. atroviride on tomato is demonstrated through degradation of IAA in the rhizosphere and ACC deaminase activity (Gravel et al., 2007). A putative sequence of ACC-deaminase found in Trichoderma genome was confirmed by gene silencing through RNAi (Viterbo et al., 2010; Kubicek et al., 2011). Expression of dicarboxylate transporter LjALMT4 responsible for carbohydrate translocation in plants was reported in Lotus japonicas genome by Takanashi et al. (2016). The gene silencing strategy of Hb1 gene to enhance NO production and up-regulation of $\mathrm{CBF}$ regulon could be a way to engineer crops in improving cold tolerance (Sehrawat et al., 2013). Kumari et al. (2015) reported IST to salinity in soybean by Pseudomonas sp. AK-1 and Bacillus sp. SJ-5 inoculation. Results indicated that superior tolerance to salt stress may be observed due to proline accumulation and lipoxygenase activity.

Koussevitzky et al. (2008) reported that Apx1, a gene coding for cytosolic ascorbate peroxidase 1 is specifically required for tolerance to drought and heat stress in Arabidopsis. Ectoine is a compatible osmolyte responsible for salt tolarance in Halomonas elongata OUT30018. Three genes for ectoine biosynthesis were cloned and transferred to tobacco plant (Nicotiana tabacum L.) cv Bright Yellow 2 (BY2) which caused increase in tolerance to hyperosmotic shock by accumulation of ectoine and exhibited normal growth under such conditions (Nakayama et al., 2000). Identifying the genes and their regulation helps breeders in generating better varieties for stress tolerance. Use of multi-omics strategies yield highly efficient and reliable outcome that are useful to facilitate methodical experiments (Figure 2). Chilling tolerance in Miscanthus grass is a desirable trait that often varies in different cultivars. Molecular expression of relevant genes for the accumulation of carbohydrates creates differentiation among varieties for chilling tolerance. The impairment of tolerance among varieties can be predicted by molecular marker of sensitive genes like TF MsCBF3 expressed in sensitive genotypes (Purdy et al., 2013).

Stress due to submergence affects more than 15 million hectares of rainfed lowland rice in different parts of Asia (Neeraja et al., 2007). Thirteen percent of the total land area of the world is affected by problems of flooding or anoxia (Cramer et al., 2011). In rice, submergence tolerance is governed by a single major quantitative trait locus (QTL) found on chromosome 9 (Toojinda et al., 2003). Neeraja et al. (2007) used molecular markers for Sub1 gene in backcross breeding program with recurrent parant Swarna. This Sub1 provides tolerance in sensitive mega varieties. Sub1A is now confirmed of being the primary contributor to submergence tolerance (Septiningsih et al., 2009). This QTL has provided a great opportunity for marker assisted backcrossing (MAB) for developing submergence tolerance in mega varieties. 


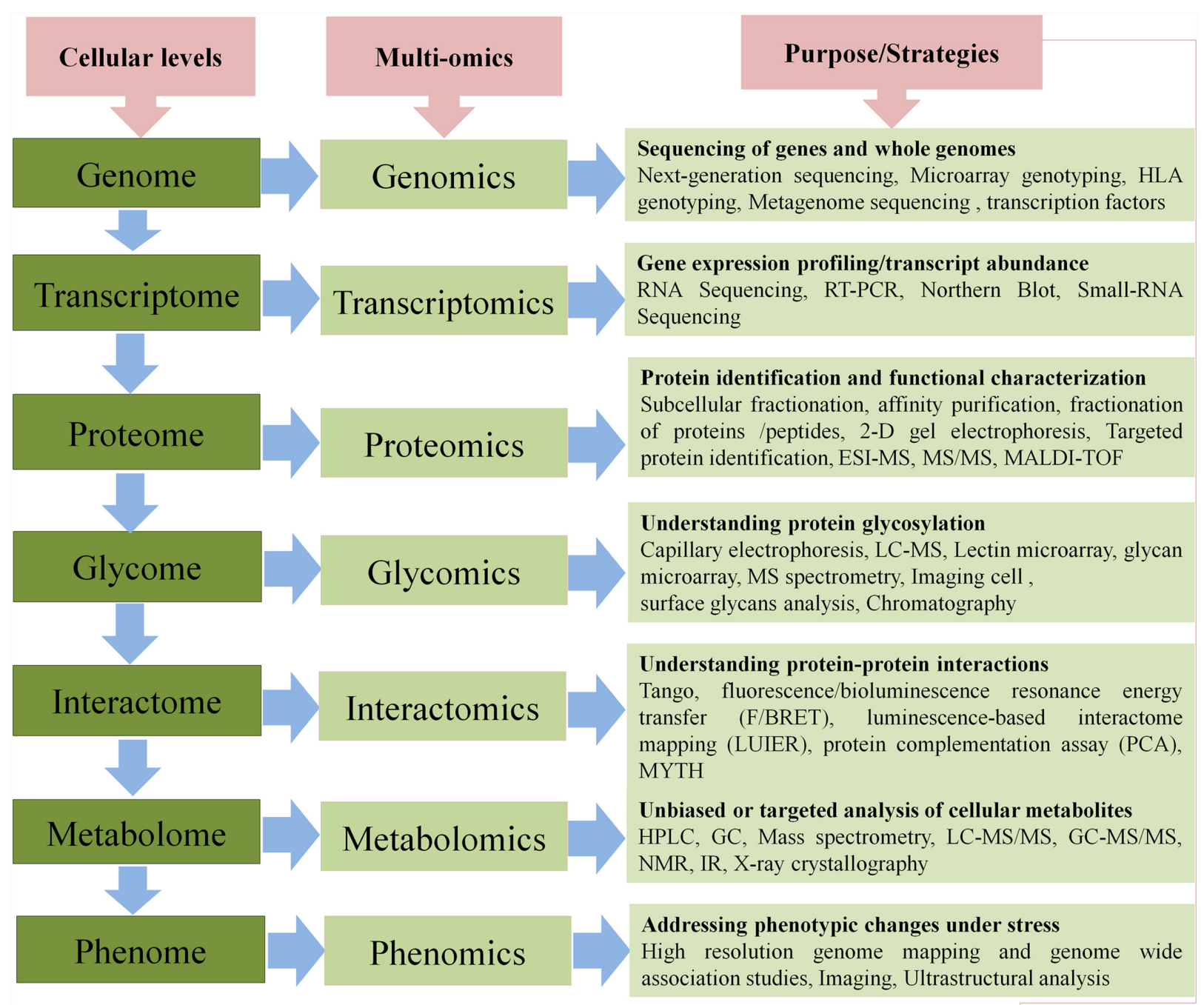

- Genes, proteins \& metabolites in response to stress/microbial interactions

- New functions to genes, proteins \& metabolites

- Temporal \& spatial monitoring of cell physiology, deposits and ultrastructural changes

- New metabolic pathways

- Reverse genetics (from metabolites to proteins to genes)

- Gene network mapping/ interconnections, signature/signal molecules, phenotype

Outcome

Identification

Characterization \&

Detection

FIGURE 2 | Cellular level components, multi-omics approaches to address different levels and the strategies that help identify the outcome of the impact of abiotic stresses or impact of microbial-interactions.

Genomic analysis of both the host and associated microbial communities especially phyllosphere-associated microbial communities permits to access the system involved for the smooth functioning of associative interactions (Figure 2). Several studies have outlined the role of different genes from associated bacteria. Plants donate indispensible moleculr counterparts to facilitate and maintain the biological system involved at the associative interface. The genotypic diversity of plants has significant influence on the interactive process. The response of the roots of SUNN1 Medicago truncatula toward elevated levels of nitrate gets markedly affected with the advent of associative rhizobia because SUNN1 exhibited no impact showing the response of SUNN1 under limiting nitrogen environment in presence of associative rhizobia (Jin et al., 2012). There are evidences on the influence of Nod factors from associative microbes on the pattern of root development and smooth functioning of symbiotic association (Olah et al., 2005; Oldroyd, 2013). Unlike nodulating plants, widely cultivated cereals lack a system to acquire nitrogen with the help of nodulation. Some diazotrophic microbes manage to enter and colonize root tissues via mechanical injuries caused during root growth (Gaiero et al., 2013). However, knowledge of such interactions is scarce. 


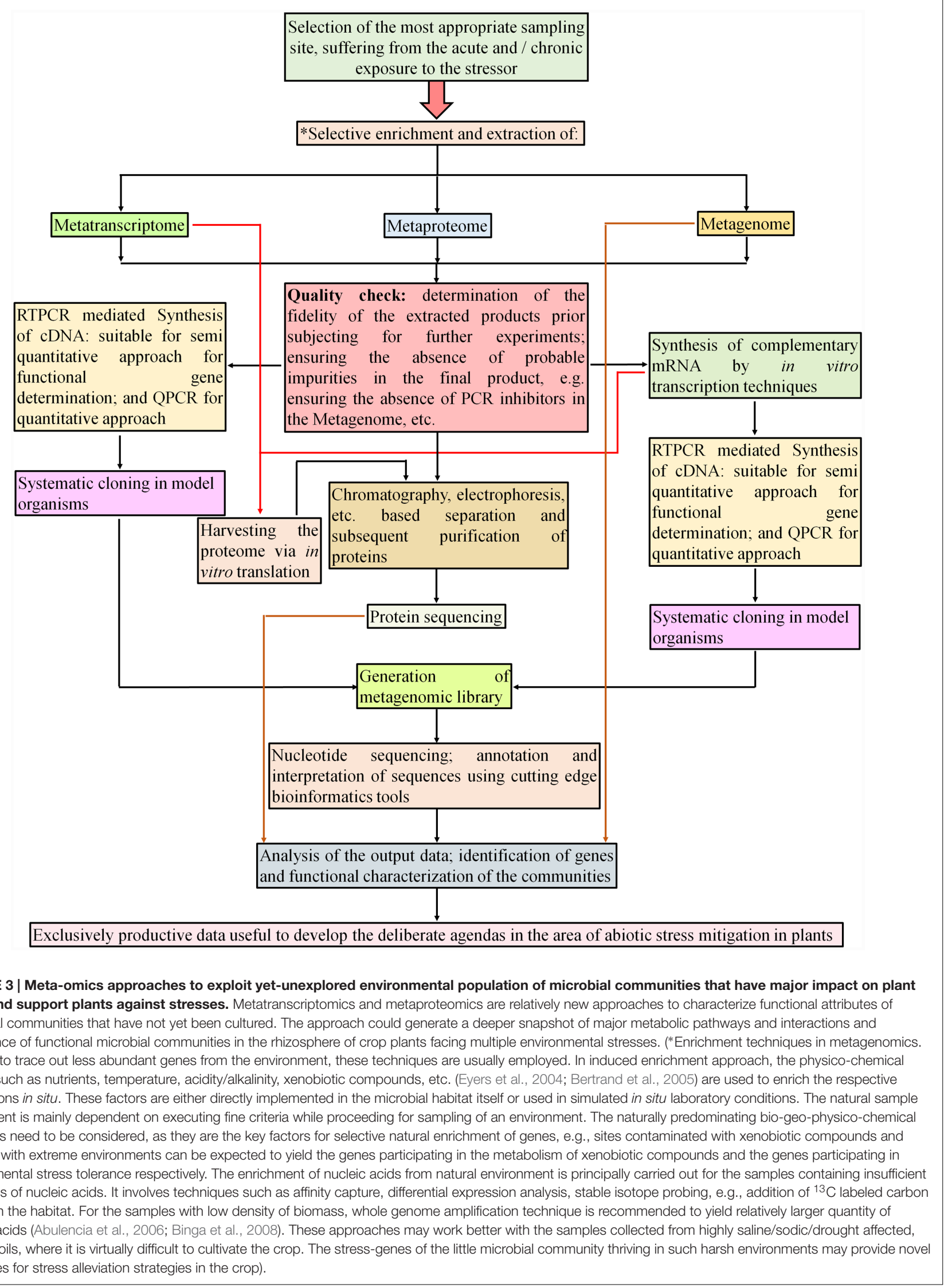




\section{METAGENOMICS}

The culture-independent approach for the analysis of microbial communities has been a powerful tool for resolution of yetuncultured, unseen microbial diversity that plays various role in the plant rhizosphere (Chen and Pachter, 2005) (Figure 3). The approach referred to as metagenomics enables the user to acquire data related to the habitat-specific distribution of microbial communities with plant growth promoting (PGP), biocontrol, antibiotic producing and xenobiotic degrading traits. The approach helps to elevate likelihood of successfully directed attempts made to explore novel culturable flora from particular niches (Handelsman et al., 2007). High-throughput metagenomic sequencing is proving to be an extremely useful tool for improved understanding of PGP rhizobacterial communities (Figure 3). In a study on potato endophytes, two types of ACC-deaminase genes (acdS) homologous to that of Pseudomonas fluorescens for stress alleviation were found from PCR analysis. Analysis of clones present in metagenomic libraries helped in identifying entire acdS operon from uncultivated endophyte and revealed a transcriptional regulator gene $a c d R$ at upstream of acdS. This operon was found prominently in the genus Burkholderia (Nikolic et al., 2011). Escherichia coli clones from a pond water metagenomic library were studied to identify salt tolerance genes in uncultivable bacteria by growing at inhibitory $\mathrm{NaCl}$ concentrations of $750 \mathrm{mM}$. Genes from two clones encoding for proteins similar to a putative general stress protein (GspM) having GsiB domain with a putative enoyl-CoA hydratase (EchM) identified to have a role in salt tolerance. After purification, EchM was found to have crotonyl-CoA hydratase activity (Kapardar et al., 2010). These genes are of great utility in developing salt tolerant recombinant bacteria and also transgenic plants. Metagenomic study of an acid mine drainage $250 \mathrm{~m}$ belowground revealed the presence of mechanisms of adaptation to cold. Genes related with the survival at low temperature like anti-freeze protein, cold-shock proteins, compatible solutes production pathways and $\mathrm{pH}$ homeostasis were found in the metagenome of acid mine drainage (Liljeqvist et al., 2015). Such metagenomics data help to finding out new genes and mechanisms for cold stress alleviation. The role of bacterial endophytes that reside inside roots is largely unexplored because endophytic microbes which are cultured successfully represent only a fraction of the whole bacterial community that inhabit root interiors. Sessitsch et al. (2012) described endophytic bacterial residents of rice roots with the help of metagenomics approach. Metagenomic sequences obtained from endophytic cell extracts revealed that metabolic processes pertaining to the endophytic life style and functional features like quorum sensing and detoxification of ROS have their role in improving plant stress resistance (Sessitsch et al., 2012). Microbial communities have a fundamental impact on plant health and productivity. As a community, microbes interact with each other and with the host. This is a key phenomenon that increases resistance to diseases and stresses. To know the microbiome composition and describe its diversity and function, global approaches like metagenomics, metatranscriptomics and metaproteomics are being applied (Figure 3). Metagenomics also reveals functional potential of microbial communities in terms of the abundance of the genes involved in particular metabolic processes linked with stresses or stress alleviation mechanism. Similarly, metatranscriptomics can reveal kingdomlevel changes in rhizosphere microbiome structure (Turner et al., 2013b) and metaproteomics can reflect community-wide gene expression, protein abundance and putative proteins that can be linked with functions after bioinformatics analysis (Turner et al., 2013b). Diversity profiling and colonization studies using metagenomics can also reveal quantitative colonization of a given host under the influence of stressor. This can yield valuable knowledge regarding stressor-induced alterations in the taxonomic and functional diversity of colonizing population if coupled with metatranscriptomic analysis (Turner et al., 2013b) (Figure 3). The coupled analysis thus achieved significantly help in understanding mitigation of stressor-influence over colonization process.

\section{TRANSCRIPTOMICS}

Comparison of transcriptome profiles is helpful in identifying different sets of transcripts responsible for differences between two biologically different expressions in various conditions (Bräutigam and Gowik, 2010). Use of mRNA sequencing analysis and microarray technique to generate transcriptome level information is one of the important methodologies employed for studying plant-microbe interactions (Akpinar et al., 2015; Budak and Akpinar, 2015; Wang et al., 2016). Next-generation RNA sequencing study on Sinorhizobium meliloti revealed induction of genes for stress response in IAA overproducing strains (Defez et al., 2016). This study compared transcription profile of two S. meliloti strains, wild-type strain-1021 and an IAA overproducing derivative RD64. The genes coding for sigma factor RpoH1 and other stress responses were found to induce IAA overproducing strain of S. meliloti. Alavi et al. (2013) identified spermidine as a novel plant growth regulator during abiotic stress by transcriptome analysis of rapeseed and its symbiont Stenotrophomonas rhizophila.

Different miRNAs in rice, Medicago, Phaseolus, Arabidopsis and other plants have a regulatory role under abiotic stresses like drought, salinity and cold (Trindade et al., 2010). miRNAs are non-coding RNAs of 19-23 nucleotide length having regulatory role in several biological processes (Budak et al., 2015). Regulatory role of miR393 was found for salinity tolerance in Arabidopsis overexpressing osaMIR393 exhibit tolerant to salt excess (Gao et al., 2011). Zhao et al. (2009) reported miR169 alleviating salinity and drought stress in rice by modulating expression of a nuclear transcription factor YA (NF-YA). In tomato, plants overexpressing miR169c which controls expression of gene(s) involved in stomatal activity confer drought tolerance (Zhang et al., 2011). Bvu-miR13 regulates WDrepeat proteins which plays crucial role in stress tolerance in cucumber (Li et al., 2014). Apart from regulating TFs, miRNAs also target stress signaling pathways which are responsible for root development, leaf morphogenesis and stress response (Curaba et al., 2014). Thirteen mature miRNAs were identified using in silico approach in B. vulgaris plants (Li et al., 2015). 
The activity of superoxide dismutases SOD1 and SOD2 mRNAs are targeted by miR398 that has a role in reducing ROS and secondary effects of abiotic stress (Kantar et al., 2011). Diverse classes of miRNAs alleviate stress by regulating differential cellular responses and metabolic processes like transcriptional regulation, auxin homeostasis, ion transport and apoptosis ( $\mathrm{Li}$ et al., 2010). miRNA is also found to regulate aluminum stress response in plants (Lima et al., 2011). Comparison of miRNA expression in two different rice subspecies, japonica and indica differing in aluminum tolerance was done. RT-qPCR approach revealed 16 different kinds of responses of miRNA indicating a complex response under aluminum stress.

UV-B radiation and flooding (hypoxia) affects plants by inducing irreversible damage by generation of ROS (Blokhina and Fagerstedt, 2010). The up-regulation of SOD proteins and miR398 down-regulation is crucial under oxidative stress in Arabidopsis (Sunkar et al., 2006). Induction of miR398 and down-regulation of miR395 was observed in alleviating UV-B stress in Populus tremula (Jia et al., 2009). Low temperature severely affects sugar beet seedlings and sugar recovery from final harvest. Transcriptome profile of cold stressed plants was done by high throughput RNA sequencing from leaves and roots (Moliterni et al., 2015). Up-regulation of CBF3 was reported from root tissues faster than the leaf tissues. Genes from $A P 2 / E R F$ family that were known to participate in jasmonic acid mediated responses were also upregulated during cold stress (Licausi et al., 2013).

\section{PROTEOMICS}

Proteins play a crucial role in expressing plant stress responses since they directly reflect shaping of a phenotypic trait. Proteomic studies therefore, have become powerful tools for the exploration of physiological metabolism and protein-protein interactions in microbes and plants (Figures 2 and 3). The implications of proteomics is important for intra- and inter-microbial species and host-microbe interactions, where host-mediated signaling and tactic responses of related microorganisms are involved (Kosova et al., 2015). Such studies lead to generate a deeper understanding of the regulation of biological system by identifying several proteins as signal of changes in physiological status due to stress or factors responsible for stress alleviation (Silva-Sanchez et al., 2015). Therefore, a comparative analysis in stressed, non-stressed and microbe-associated plants can help to identify protein targets and networks. Proteomic studies for stress responses in crops have been studied extensively in plants including Arabidopsis, wheat (Triticum aestivum), durum wheat (Triticum durum), barley (Hordeum vulgare), maize (Zea maize), rice (Oryza sativa), soybean (Soybean max), common bean (Phaseolus vulgaris), pea (Pisum sativum), oilseed rape (Brassica napus), potato (Solanum tuberosum) and tomato (Lycopersicon esculentum) (Liu et al., 2015; Kosova et al., 2015; Xu J. et al., 2015; Wang et al., 2016). Such studies reflected dynamic alternations in protein functional groups, proteins of signaling and regulatory pathways, TFs, protein metabolism, proteinprotein interactions at interface, proteins and enzymes conferring several stress-related compounds, functions of structural proteins associated with the cell wall and cytoskeleton and identification of putative proteins using bioinformatics tools (Kosova et al., 2015).

Chen et al. (2015) assessed mechanisms of cold acclimation in alfalfa by proteomic analysis in cold tolerant (ZD7) and cold sensitive lines (W5). Cassava, a tropical crop sensitive to low temperature can modify its metabolism and growth to adapt to the cold stress. Proteomic study was carried out to understand the mechanism behind cold-tolerant process. Twenty differential proteins were found to have similar patterns in apical expanded leaves of cultivars SC8 and Col1046. Expression of proteome profile was found to link closely with changes in photosynthetic activity and peroxiredoxin expression levels. Principle component analysis reflected that electrolyte leakage (EL), chlorophyll content, and malondialdehyde (MDA) accumulation were the physiological indexes in determining cold tolerance in cassava (An et al., 2016).

A leucine-rich repeat receptor kinase $(S r l k)$ was reported to function as an upstream regulator of salinity responsive genes in Medicago truncatula. It was found to be involved in sensing salinity stress and its response (de Lorenzo et al., 2009). This study revealed an interesting mechanism of sensing salinity stress. Based on proteome profile of barley at different water stress conditions, Ghabooli et al. (2013) proposed that $P$. indica mitigate drought stress by photosynthesis stimulation releasing energy and higher antioxidant production. Wang et al. (2016) screened a novel gene Ds-26-16 from the cDNA library of 4M salt-stressed Dunaliella salina. This gene was found to confer salt tolerance in E. coli, Haematococcus pluvialis and tobacco. Proteomics data by iTRAQ studies reflected that Ds-26-16 up-regulates TFs for stress responses like ROS alleviation, osmotic balance, and energy metabolism in E. coli.

The diversity of metabolic pathways existing amongst the microbes makes them more responsive toward stress conditions. It is important in the protocols implemented for the elucidation of plant-elaborated responses against stress. Unlike routine proteomics approaches which are more focused toward a single organism, the role of metaproteomics that deals with multiple metabolic interactions occurring simultaneously in an ecosystem is the need of the time (Figure 3 ). This could help to resolve better significance of interdependence between various microbial communities in an agro-ecosystem alongwith their interactions with the host plant. The protocols for protein extraction from the environmental samples are most important success-milestone in the area of metaproteomics (Figure 3). Recent advancements in protein sequencing are the key step for the identification of proteins from diverse species (Cordwell et al., 1995, 1997; Shevchenko et al., 2001). The complexity of metaproteome makes resolution and analysis quite difficult. However, recent approaches in extraction and analysis of successful environmental metaproteome could yield decisive output and establish a better correlation among the omics data and response mechanisms among organisms toward stresses (Schulze, 2005; Schweder et al., 2008).

Most of the environmental proteomic experiments are limited to model organisms cultured. They particularly highlight the 
exceptional ability of the organisms, e.g., tolerance to salinity, sodicity, temperature, low water availability, toxic metals and radiation etc. The proteomic studies of the organisms lead toward better understanding of fine mechanisms being executed by them. Moreover, the same also stands helpful for the confirmation of the probability of their exploitation for expected induction of the said metabolism in diverse environments. The laboratory experiments allow a better grasp of the protein profile in a controlled environment, however, it contrasts the fact that the expression profile varies with changes in environmental conditions.

The Haloarchea and Halobacteria are gaining strong attention in present era due to their ability to thrive in high salt environments. PGP ability of organisms can be implemented conveniently in saline and sodic soils for the alleviation of respective stresses encountered by the crops. This will prove beneficial for yield improvement in stress-prone areas. Harvesting and implementing metabolites that can confer halotolerance from microorganisms growing in the area of high salt stress with other combined stresses may find important applications in the crop improvement programs. Culturing of these organisms under in situ stress conditions in laboratory is the simplest approach to induce the production of effective metabolites that when applied on plants, could impart tolerance against stresses. Similarly, to cope with the most agonizing problem of xenobiotic compounds, the genus Pseudomonas is the best considered one, particularly because of its unique ability to degrade enormous amount of carbon sources, especially of xenobiotic nature. The hydrocarbon degradation by Pseudomonas is well known. The proteomic experiments for Pseudomonas have been designed principally to focus on the recalcitrant, xenobiotic compounds in addition to the toxic organic pollutants (Lupi et al., 1995; Reardon and Kim, 2002; Kim et al., 2007). Species of Pseudomonas have been well characterized for their PGP traits such as siderophore production (Ferret et al., 2014; Cunrath et al., 2015), secretion of plant growth stimulating substances (Pereira and Castro, 2014; Balcazar et al., 2015; Sorty et al., 2016), and biocontrol against phytopathogenic organisms (Chet and Inbar, 1994; Natsch et al., 1994; Acebo-Guerrero et al., 2015; Wang et al., 2015). Characteristic versatile metabolic scope and unique biofilm forming ability of the members of this genus (Kertesz et al., 1993; Sauer et al., 2002, 2004; Arevalo-Ferro et al., 2005; VerBerkmoes et al., 2006) permits these species to thrive well under diverse environmental conditions, thus making them most effective inoculants for field application.

The proteomic exploration of methylotrophic bacteria is also an active area of interest today. Methylotrophs constitute a major portion of phylosphere community, typically leaf surface, where one-carbon substrate, methanol is easily available via transpiration activity. Pink-pigmented facultative methylotrophic (PPFM) bacteria are predominant and explored largely for their ability to release plant-growth regulation molecules (Meena et al., 2012; Araujo et al., 2015; Dourado et al., 2015). Many studies have successfully demonstrated PGP potential of these organisms under various conditions (Tani et al., 2012; Yim et al., 2013). Detailed investigations about the proteomic insights of these characteristic phyllospherecommunity members helped to get novel ideas regarding involvements of proteins in survival mechanism of organisms under relatively harsh environments, generally encountered on leaf surfaces, where in addition to intense radiation, there exists frequent scarcity of nutrients. Additionally, their potential to secrete plant-growth regulators may come to a large-scale execution. It is, therefore, needful to elucidate deep molecular insights of PGP microbial communities, chiefly involved in stress alleviation to acquire the data regarding mechanisms involved in such processes. The identification of proteins involved in these processes is sufficient to create a boom in stress alleviation strategies at the molecular level where direct implementation of active molecules were thought upon instead of employing the whole organism.

In plants, the study of protein expression of different lines is helpful in selecting cold-tolerant lines for crop improvement. It is evident from earlier studies that cold-tolerant lines showed 14 differential proteome expressions in cold acclimation of sunflower (Balbuena et al., 2011). Proteome analysis also reveals possible mechanisms for chilling mitigation in plants and cross tolerance mechanisms (Yuan et al., 2015; Meng et al., 2016). Once the database of responsive and blocked genotypes is made for particular abiotic stress, it can be used as a marker in differentiating stress responsive genotypes. Santos et al. (2016) has made GeLC-MS/MS based proteomic profiling for large-scale identification of proteins from Araucaria angustifolia embryogenic cell lines. In total, 106 proteins were differentially expressed between the responsive and blocked type lines for abiotic stress. Two proteins at early stage were identified to be related with blocked cell lines only. These proteins can be an indicative to blocked cell lines at early stage of plant development.

\section{METABOLOMICS}

The scope of metabolomics involves characterization of all the metabolites elaborated by an organism under the influence of given environmental conditions. The metabolome of an organism directly correlates with diverse pathways being operated inside the cell which in turn reflects the availability of corresponding genetic information. The metabolome varies largely with alterations in surrounding environment that induce direct physiological alterations in an organism (Bundy et al., 2005). Similar situations of physiological state are expected in those organisms which are supposed to thrive well under the stress conditions. It is, therefore, important to acquire detailed knowledge of metabolome of an organism both in normal and under-stress physiological status, the subtraction of which will yield the presence/absence of typical signature metabolites of interest. This will be helpful in identifying alterations induced within the pathways and induction of typical stress-inducible genes (Figure 2). Metabolomics is increasingly being used for generating deep insights into abiotic stress responses (Jorge et al., 2015; Jia et al., 2016). Recent high throughput developments in the area of molecular detection techniques have given boost to metabolomics studies (Hollywood et al., 2006; Morrow, 2010). Studies highlight the presence of different bioactive chemicals (Burns et al., 2003; Ketchum et al., 2003) in plant metabolome. 
This observation correlates with the reports pertaining to the identification of various signal molecules secreted by plants to attract and induce important biochemical pathways in colonizing microbial population (Zhang and Cheng, 2006; Micallef et al., 2009).

Trichoderma spp. produce auxins which stimulate plant growth by alleviating stress (Contreras-Cornejo et al., 2009). Two secondary metabolites, harzianolide and 6-pentyl-a-pyrone of Trichoderma was reported to exhibit auxin-like effects in etiolated pea stem (Vinale et al., 2008) and enhance plant growth. Variations induced by changing environmental situations in plant metabolism also affect secretion pattern and nature of secreted molecules (Martínez-Cortés et al., 2014) thereby affecting the level of root colonization. Microbial molecular signaling mechanisms in the rhizosphere are also affected in a similar manner but this is yet to be explored.

Plants accumulate different metabolites like trehalose, glycine betain, IAA etc. in response to abiotic stresses. Allen et al. (2009) reported that mere accumulation of a specific compound does not indicate stress tolerance, but it is the adjustment of flux to different pathways of defense and growth which decides tolerance. Modulation of stoichiometry and metabolism is reported as mechanisms to maintain optimum fitness in plants (Rivas-Ubach et al., 2012). Time-series experiments with Arabidopsis thaliana indicated that metabolic activities respond more quickly than that of transcriptional activities to abiotic alterations (Caldana et al., 2011).

The conditions, available within surrounding environment influence pathways operating in the microbial cell, thereby affecting the metabolome. It is evident that the same must affect their overall performance in surrounding microenvironment and within the ecosystem to a greater extent (Tringe et al., 2005; Raes and Bork, 2008; Jiao et al., 2010) in terms of the interactions evident within and between the inhabitants therein. Microbial metabolic products have been involved in both direct as well as indirect plant growth promotion. It is well known that many of the rhizosphere bacteria show the ability to produce plant growth stimulating biomolecules like cytokinins, gibberelins, etc. (Williams and de Mallorca, 1982; Robin et al., 2006). Variety of microbial metabolites including IAA, gibberelins, siderophores serve the purpose. Recently the IAA produced by Pseudomonas sp., Rhizobium sp., Enterobacter sp., Pantoea sp., Marinobacterium sp., Acinetobacter sp., and Sinorhizobium sp., has been shown to influence the germination and seedling growth in wheat under saline conditions (Sorty et al., 2016). Similarly, the strains of Bacillus sp. having phosphate solubilizing potential successfully improved the yield and quality of fennel in semiarid saline soil (Mishra et al., 2016). The solubilization of phosphate is mainly attributed to the low molecular weight organic acids produced by the microbes. Microbial siderophores also play an important role toward the biological availability of iron to plant roots, for instance, the siderophores produced by Pseudomonas fluorescens C7 successfully supplemented the iron to Arabidopsis thaliana (Vansuyt et al., 2007). Although the siderophore production by the microbes seems influenced by biogeochemical factors, they also help in the alleviation of the stress imposed by heavy metals (Diels et al., 2002).
Many microbes show high degree of environmental dependency for optimal siderophore production. Sorty and Shaikh (2015) reported reduced iron uptake by both sediment as well as soil magnetotactic bacteria under acidic conditions and the probable cause was attributed to the conversion of $\mathrm{Fe}^{+++}$to $\mathrm{Fe}^{++}$ under acidic conditions that could have interfered with the siderophore mediated iron uptake system. This signifies the need of keen evaluation of in situ mechanisms influencing microbial metabolism. Moreover, the majority of these metabolites are yet to be identified. The cutting edge metabolomics technology could serve as a powerful tool for the evaluation of these metabolites and environmental interventions in the microbial metabolism in situ. Many microbes from the ecosystem show interdependence with respect to the substrate utilization and metabolite exchange forming the basis of succession. Moreover, the same is applicable in the area of biodegradation of recalcitrant as well as xenobiotic compounds too, where cometabolism is shown to play the principle role. This involves simultaneous oxidation of non-substrate compounds with that of true substrates during vigorous growth of bacteria. The members belonging to the genera Pseudomonas, Flavobacterium, Bacillus, Azotobacter, Microbacterium, Hydrogenomonas, Achromobacter and Xanthomonas are predominant co-metabolisers in the ecosystem (Beam and Perry, 1973). This property of cometabolism has significant implications in the studies depicting biochemical pathways, particularly involved in the metabolism of polycyclic and polyaromatic compounds (Horvath, 1972; Chauhan et al., 2008). Metabolomics studies of these processes provide the information on the enzymes involved in the conversion and pathways they participate in, thereby raising the probability of their large-scale exploitation to the sites where the native ecosystems have encountered the stress conditions due to the accumulation and/or contamination of xenobiotic and recalcitrant compounds. Many hydrocarbons such as $p$-isopropyltoulene, $n$-butylcyclohexane, $n$-butylbenzene, ortho and para xylene etc. are actively co-metabolized by the members of genus Nocardia (Davis and Raymond, 1961; Raymond et al., 1967). The inimitable metabolic power of such organisms highlight strong implementable ability of PGP members of such genera to remediate stresses imposed by contaminated soils on crop and thus pave the way for bioremediation.

The quantitative metabolomics studies also permit measurements of cellular processes with high accuracy and precision (Noack and Wiechert, 2014). The high-throughput mass spectrometric profiling of cellular metabolites of plantassociated microbes under the influence of stressors could reveal the level of interference by the stressor in the overall cellular homeostasis (Figure 2). The communication between plants and soil microbial community represents a bilateral process involving root exudates and microbial-elaborated signal response molecules (Oldroyd and Downie, 2008; Inceoglu et al., 2011; Peiffer et al., 2013). The augmentation of rhizosphere with exogenous microbial metabolites also needs prior insights into the microbial metabolism. This includes the ratio of cellular abundance, biomolecules elaborated under normal and optimal circumstances, quantitative leakage, participation of plant signals in the cascade and resulting counter 
response of microbes. It could be thoughtful to enrich such biomolecules in the rhizosphere that are down-regulated due to the influence of the stressor. Similar is applicable to the probable management of stressor-responsive biomolecules influencing overall communication process between the host and microbe. The altered plant root exudation under the influence of stressor fails to induce cascades described above in microbial systems that transpire otherwise.

The accessibility of nucleotide data has been one of the value additions for metabolomics studies (NCBI). This ensures smoothening of future experiments targeting systems biological perspectives. The recruitment of microbialoriginated biomolecules and/or in vitro synthesized metabolites under simulated conditions in the phyllosphere have been demonstrated recently (Sorty et al., 2016). This mainly deals with the fact that live microbes, under stressed environment fail to express vital genes for PGP activity. However, the impact of enrichment of rhizosphere with the appropriate quantity of such metabolites needs thorough evaluation. The insights to host metabolomics are also beneficial to acquire knowledge regarding the influence of host on post-colonization metabolism of microbes. This could open the gateway for simulation of highly complex endophytic environment.

Rhizosphere community also represents multifaceted system involving biogeochemical cycling and exchange of nutrients, leaving an excellent platform for gaining deep insights in to the systems microbiology. Enormous pathways are simultaneously operated by diverse members of microbial community. Environmental factors have maximum influence on the smooth operation of such pathways. Arrival of stressor/altered environmental situation ultimately diverts overall functionality of microbial system, thereby inducing variation in the community structure. The understanding of biochemical links within and between the members of an ecosystem is necessary to acquire the phenotype-level knowledge in a given biogeochemical state of event (Breitling et al., 2008).

\section{CONCLUSION}

Plant responses toward various abiotic stresses and microbemediated stress mitigation strategies in plants have been studied on sound grounds of molecular, biochemical, physiological and ultrastructural parameters. Such studies have been carried out encompassing different omics approaches (genomics, metagenomics, metatranscriptomics, proteomics, metaproteomics and metabolomics) that strengthened our understanding behind the mechanisms of microbial interactions, gene cascades and metabolic pathways, accumulation and enhancement of various metabolites, proteins, enzymes and

\section{REFERENCES}

Abulencia, C. B., Wyborski, D. L., Garcia, J. A., Podar, M., Chen, W., Chang, S. H., et al. (2006). Environmental whole-genome amplification to access microbial populations in contaminated sediments. Appl. Environ. Microbiol. 72, 3291-3301. doi: 10.1128/AEM.72.5.3291-3301.2006 up- and down regulation of different genes. Such studies could yield dynamic data related to combined responses of plants to multiple stresses, and the same is also pertinent with the naturally associated or artificially inoculated microorganisms. These studies provide new directions for improvising the existing protocols in the field of plant-microbe interactions under stress, and use of microorganisms and microbial metabolite molecules for alleviation of diverse stresses encountered by plants. The expected outcomes are facilitating germination, superior sustenance, enhanced ability to combat adverse conditions of environment and superior yield in plants because of the use of microbe-elaborated molecules. Due to limitations regarding the sustenance of microbes in diversity of stress environments and variable responses at phenotypic level, it is always suitable to implement microbe-derived natural products that are capable of performing expected job of stress mitigation irrespective of the environmental situations. To conclude, we strongly advocate that there is a need to put greater attention on indepth studies pertaining to identification, trait characterization, compatibility assessment, delivery methods and impact of application of microbes isolated from diverse environmental conditions for the mitigation of abiotic stresses in crop plants. We need to find out new roles for microbial metabolites that are being produced under stressed environmental conditions. Established evidences exist to support the role of microbemediated plant interactions in stress mitigation under diverse climatic and edaphic conditions. However, more focused omics-based research data generation following integrated approaches encompassing genomics, metagenomics, proteomics and metabolomics studies on specific plant-microbe-abiotic stress system will be needed to resolve many facts behind precise mechanisms of stress tolerance/mitigation in the crop plants.

\section{AUTHOR CONTRIBUTIONS}

KM proposed concept, KM and AS collected data and wrote the manuscript, KC and UB collected data, AP and PG added abiotic stress in plants, DS, RP, PS, HS, KK, VG, and PM contributed for omics data and edited the manuscript.

\section{ACKNOWLEDGMENTS}

Financial assistance from Indian Council of Agricultural Research (ICAR), India under Application of Microorganisms in Agriculture and Allied Sectors (AMAAS-NBAIM/AMAAS/2014$15 / 1 \mathrm{a}(6) / 223)$ and DST-SERB Young Scientist scheme (SB/YS/LS-218/2013) is gratefully acknowledged.

Acebo-Guerrero, Y., Hernández-Rodríguez, A., Vandeputte, O. Miguélez-Sierra, Y., Heydrich-Pérez, M., Ye, L., et al. (2015). Characterization of Pseudomonas chlororaphis from Theobroma cacao L. rhizosphere with antagonistic activity against Phytophthora palmivora (Butler). J. Appl. Microbiol. 119, 1112-1126. doi: 10.1111/jam. 12910 
Adediran, G. A., Ngwenya, B. T., Mosselmans, J. F. W., and HealK, V. (2016). Bacteria-zinc co-localization implicates enhanced synthesis of cysteine-rich peptides in zinc detoxification when Brassica juncea is inoculated with Rhizobium leguminosarum. New Phytol. 209, 280-293. doi: 10.1111/nph. 13588

Agarwal, S., and Grover, A. (2006). Molecular biology, biotechnology and genomics of flooding-associated low $\mathrm{O} 2$ stress response in plants. Crit. Rev. Plant Sci. 25, 1-21. doi: 10.1080/07352680500365232

Ahmad, P., Hashem, A., Abd-Allah, E. F., Alqarawi, A. A., John, R., Egamberdieva, D., et al. (2015). Role of Trichoderma harzianum in mitigating $\mathrm{NaCl}$ stress in Indian mustard (Brassica juncea L) through antioxidative defense system. Front. Plant Sci. 6:868. doi: 10.3389/fpls.2015.00868

Akpinar, B. A., Kantar, M., and Budak, H. (2015). Root precursors of microRNAs in wild emmer and modern wheats show major differences in response to drought stress. Funct. Integr. Genomics 15, 587-598. doi: 10.1007/s10142-0150453-0

Alameda, D., Anten, N. P. R., and Villar, R. (2012). Soil compaction effects on growth and root traits of tobacco depend on light, water regime and mechanical stress. Soil Tillage Res. 120, 121-129. doi: 10.1016/j.still.2011.11.013

Alami, Y., Achouak, W., Marol, C., and Heulin, T. (2000). Rhizosphere soil aggregation and plant growth promotion of sunflowers by exopolysaccharide producing Rhizobium sp. strain isolated from sunflower roots. Appl. Environ. Microbiol. 66, 3393-3398. doi: 10.1128/AEM.66.8.3393-3398.2000

Alavi, P., Starcher, M. R., Zachow, C., Müller, H., and Berg, G. (2013). Rootmicrobe systems: the effect and mode of interaction of stress protecting agent (SPA) Stenotrophomonas rhizophila DSM14405T. Front. Plant Sci. 4:141. doi: $10.3389 /$ fpls. 2013.00141

Al-Garni, S. M. S. (2006). Increasing NaCl-salt tolerance of a halophytic plant Phragmites australis by mycorrhizal symbiosis. Am. Eurasian J. Agric. Environ. Sci. 1, 119-126.

Ali, S. Z., Sandhya, V., Grover, M., Kishore, N., Rao, L. V., and Venkateswarlu, B. (2009). Pseudomonas sp. strain AKM-P6 enhances tolerance of sorghum seedlings to elevated temperatures. Biol. Fertil. Soil 46, 45-55. doi: 10.1007/ s00374-009-0404-9

Allen, D. K., Libourel, I. G., and Shachar-Hill, Y. (2009). Metabolic flux analysis in plants: coping with complexity. Plant Cell Environ. 32, 1241-1257. doi: 10.1111/j.1365-3040.2009.01992.x

Almoguera, C., Coca, M. A., and Jouanin, L. (1995). Differential accumulation of sunflower tetraubiquitin mRNAs during zygotic embryogenesis and developmental regulation of their heat shock response. Plant Physiol. 107, 765-773. doi: 10.1104/pp.107.3.765

Amellal, N., Burtin, G., Bartoli, F., and Heulin, T. (1998). Colonization of wheat rhizosphere by EPS producing Pantoea agglomerans and its effect on soil aggregation. Appl. Environ. Microbiol. 64, 3740-3747.

An, F., Li, G., Li, Q. X., Li, K., Carvalho, L. J., Ou, W., et al. (2016). The Comparatively proteomic analysis in response to cold stress in Cassava Plantlets. Plant Mol. Biol. Report. 34, 1095-1110. doi: 10.1007/s11105-0160987-x

Andreasson, E., and Ellis, B. (2010). Convergence and specificity in the Arabidopsis MAPK nexus. Trends Plant Sci. 15, 106-113. doi: 10.1016/j.tplants.2009. 12.001

Apel, K., and Hirt, H. (2004). Reactive oxygen species: metabolism, oxidative stress, and signal transduction. Annu. Rev. Plant Biol. 55, 373-399. doi: 10.1146/ annurev.arplant.55.031903.141701

Araujo, W. L., Santos, D. S., Dini-Andreote, F., Salgueiro-London o, J. K., Camargo-Neves, A. A., Andreote, F. D., et al. (2015). Genes related to antioxidant metabolism are involved in Methylobacterium mesophilicumsoybean interaction. Antonie Van Leeuwenhoek 108, 951-963. doi: 10.1007/ s10482-015-0548-6

Arevalo-Ferro, C., Reil, G., Gorg, A., Eberl, L., and Riedel, K. (2005). Biofilm formation of Pseudomonas putida IsoF: the role of quorum sensing as assessed by proteomics. Syst. Appl. Microbiol. 28, 87-114. doi: 10.1016/j.syapm.2004.10. 005

Arkhipova, T. N., Prinsen, E., Veselov, S. U., Martinenko, E. V., Melentiev, A. I., and Kudoyarova, G. R. (2007). Cytokinin producing bacteria enhance plant growth in drying soil. Plant Soil 292, 305-315. doi: 10.1007/s11104-007-9233-5

Aroca, R., Porcel, R., and Ruiz-Lozano, J. M. (2007). How does arbuscular mycorrhizal symbiosis regulate root hydraulic properties and plasma membrane aquaporins in Phaseolus vulgaris under drought, cold or salinity stresses? New Phytol. 173, 808-816. doi: 10.1111/j.1469-8137.2006.01961.x

Aroca, R., Vernieri, P., and Ruiz-Lozano, J. M. (2008). Mycorrhizal and nonmycorrhizal Lactuca sativa plants exhibit contrasting responses to exogenous ABA during drought stress and recovery. J. Exp. Bot. 59, 2029-2041. doi: 10. 1093/jxb/ern057

Ashraf, M., Hasnain, S., Berge, O., and Mahmood, T. (2004). Inoculating wheat seeds with exopolysaccharide-producing bacteria restricts sodium uptake and stimulates plant growth under salt stress. Biol. Fertil. Soil 40, 157-162. doi: 10.1007/s00374-004-0766-y

Atkinson, N. J., Lilley, C. J., and Urwin, P. E., (2013). Identification of genes involved in the response of arabidopsis to simultaneous biotic and abiotic stresses. Plant Physiol. 162, 2028-2041. doi: 10.1104/pp.113. 222372

Atkinson, N. J., and Urwin, P. E. (2012). The interaction of plant biotic and abiotic stresses: from genes to the field. J. Exp. Bot. 63, 3523-3543. doi: 10.1093/jxb/ ers 100

Babu, A. G., Shea, P. J., Sudhakar, D., Jung, I. B., and Oh, B. T. (2015). Potential use of Pseudomonas koreensis AGB-1 in association with Miscanthus sinensis to remediate heavy metal(loid)-contaminated mining site soil. J. Environ. Manage. 151, 160-166. doi: 10.1016/j.jenvman.2014.12.045

Bailey-Serres, J., and Voesenek, L. A. (2008). Flooding stress: acclimations and genetic diversity. Annu. Rev. Plant Biol. 59, 313-339. doi: 10.1146/annurev. arplant.59.032607.092752

Bakker, M. G., Manter, D. K., Sheflin, A. M., Weir, T. L., and Vivanco, J. M. (2012). Harnessing the rhizosphere microbiome through plant breeding and agricultural management. Plant Soil 360, 1-13. doi: 10.1007/s11104-012-1361-x

Balbuena, T. S., Salas, J. J., Martínez-Force, E., Garcés, R., and Thelen, J. J. (2011). Proteome analysis of cold acclimation in sunflower J. Proteome Res. 10, 2330-2346. doi: 10.1021/pr101137q

Balcazar, W., Rondón, J., Rengifo, M., Ball, M. M., Melfo, A., Gómez, W., et al. (2015). Bioprospecting glacial ice for plant growth promoting bacteria. Microbiol. Res. 177, 1-7. doi: 10.1016/j.micres.2015.05.001

Baltruschat, H., Fodor, J., Harrach, B. D., Niemczyk, E., Barna, B., Gullner, G., et al. (2008). Salt tolerance of barley induced by the root endophyte Piriformospora indica is associated with a strong increase in anti-oxidants. New Phytol. 180, 501-510. doi: 10.1111/j.1469-8137.2008.02583.x

Barka, E. A., Nowak, J., and Clément, C. (2006). Enhancement of chilling resistance of inoculated grapevine plantlets with a plant growth-promoting rhizobacterium Burkholderia phytofirmans strain PsJN. Appl. Environ. Microbiol. 72, 7246-7252. doi: 10.1128/AEM.01047-06

Barriuso, J., Solano, B. R., Fray, R. G., Camara, M., Hartmann, A., and Manero, F. J. G. (2008a). Transgenic tomato plants alter quorum sensing in plant growthpromoting rhizobacteria. Plant Biotechnol. J. 6, 442-452. doi: 10.1111/j.14677652.2008.00331.x

Barriuso, J., Solano, B. R., and Mañero, F. J. G. (2008b). Protection against pathogen and salt stress by four plant growth-promoting rhizobacteria isolated from Pinus sp. on Arabidopsis thaliana. Phytopathology 98, 666-672. doi: 10.1094/ PHYTO-98-6-0666

Beam, H. W., and Perry, J. J. (1973). Co-Metabolism as a factor in microbial degradation of cycloparaffinic hydrocarbons. Arch. Microbiol. 91, 87-90.

Belimov, A. A., Dodd, I. C., Hontzeas, N., Theobald, J. C., Safronova, V. I., and Davies, W. J. (2009). Rhizosphere bacteria containing 1-aminocyclopropane1-carboxylate deaminase increase yield of plants grown in drying soil via both local and systemic hormone signalling. New Phytol. 181, 413-423. doi: 10.1111/ j.1469-8137.2008.02657.x

Belimov, A. A., Dodd, I. C., Safronova, V. I., Hontzeas, N., and Davies, W. J. (2007). Pseudomonas brassicacearum strain Am3 containing 1-aminocyclopropane1-carboxylate deaminase can show both pathogenic and growth-promoting properties in its interaction with tomato. J. Exp. Bot. 58, 1485-1495. doi: 10. 1093/jxb/erm010

Bertrand, H., Poly, F., Van, V. T., Lombard, N., Nalin, R., Vogel, T. M., et al. (2005). High molecular weight DNA recovery from soils prerequisite for biotechnological metagenomic library construction. J. Microbiol. Methods 62, 1-11. doi: 10.1016/j.mimet.2005.01.003

Bian, S., and Jiang, Y. (2009). Reactive oxygen species, antioxidant enzyme activities and gene expression patterns and recovery. Sci. Hortic. 120, 264-270. doi: 10.1016/j.chemosphere.2016.02.072 
Binga, E. K., Lasken, R. S., and Neufeld, J. D. (2008). Something from (almost) nothing: the impact of multiple displacement amplification on microbial ecology. ISME J. 2, 233-241. doi: 10.1038/ismej.2008.10

Blokhina, O., and Fagerstedt, K. V. (2010). Reactive oxygen species and nitric oxide in plant mitochondria: origin and redundant regulatory systems. Physiol. Plant. 138, 447-462. doi: 10.1111/j.1399-3054.2009.01340.x

Bolton, M. V. (2009). Primary metabolism and plant defense-Fuel for the fire. Mol. Plant Microbe Interact. 22, 487-497. doi: 10.1094/MPMI-22-5-0487

Bowen, G. D., and Rovira, A. D. (1991). "The rhizosphere: the hidden half of the hidden half," in Plant Roots: The Hidden Half, eds Y. Waisel, A. Eshel, and U. Kalkafi (New York, NY: Marcel Dekker), 641-669.

Braud, A., Jezequel, K., Bazot, S., and Lebeau, T. (2009). Enhanced phytoextraction of an agricultural Cr-, $\mathrm{Hg}$ - and $\mathrm{Pb}$-contaminated soil by bioaugmentation with siderophoreproducing bacteria. Chemosphere 74, 280-286. doi: 10.1016/ j.chemosphere.2008.09.013

Bräutigam, A., and Gowik, U. (2010). What can next generation sequencing do for you? Next generation sequencing as a valuable tool in plant research. Plant Biol. 12, 831-841. doi: 10.1111/j.1438-8677.2010.00373.x

Bray, E. A., Bailey-Serres, J., and Weretilnyk, E. (2000). "Responses to abiotic stresses," in Biochemistry and Molecular Biology of Plants, eds W. Gruissem, B. Buchannan, and R. Jones (Rockville, MD: American Society of Plant Physiologists), 1158-1203.

Breitling, R., Vitkup, D., and Barrett, M. P. (2008). New surveyor tools for charting microbial metabolic maps. Nat. Rev. Microbiol. 6, 156-161. doi: 10. 1038/nrmicro1797

Bromham, L., Saslis-Lagoudakis, C. H., Bennett, T. H., and Flowers, T. J. (2013). Soil alkalinity and salt tolerance: adapting to multiple stresses. Biol. Lett. 9:20130642. doi: 10.1098/rsbl.2013.0642

Brotman, Y., Landau, U., Cuadros-Inostroza, Á, Takayuki, T., Fernie, A. R., Chet, I., et al. (2013). Trichoderma-plant root colonization: escaping early plant defense responses and activation of the antioxidant machinery for saline stress tolerance. PLoS Pathog. 9:e1003221. doi: 10.1371/journal.ppat.100 3221

Budak, H., and Akpinar, B. A. (2015). Plant miRNAs: biogenesis, organization and origins. Funct. Integr. Genomics 15, 523-531. doi: 10.1007/s10142-0150451-2

Budak, H., Kantar, M., Bulut, R., and Akpinar, B. A. (2015). Stress responsive miRNAs and isomiRs in cereals. Plant Sci. 235, 1-13. doi: 10.1016/j.plantsci. 2015.02.008

Bui, E. N. (2013). Soil salinity: a neglected factor in plant ecology and biogeography. J. Arid Environ. 92, 14-25. doi: 10.1016/j.jaridenv.2012.12.014

Bulgarelli, D., Rott, M., Schlaeppi, K., Ver Loren van Themaat, E., Ahmadinejad, N., and Assenza, F. (2012). Revealing structure and assembly cues for Arabidopsis root-inhabiting bacterial microbiota. Nature 488, 91-95. doi: 10.1038/nature 11336

Bundy, J. G., Willey, T. L., Castell, R. S., Ellar, D. J., and Brindle, K. M. (2005). Discrimination of pathogenic clinical isolates and laboratory strains of Bacillus cereus by NMR-based metabolomic profiling. FEMS Microbiol. Lett. 242, 127-136. doi: 10.1016/j.femsle.2004.10.048

Burns, J., Fraser, P. D., and Bramley, P. M. (2003). Identification and quantification of carotenoids, tocopherols and chlorophylls in commonly consumed fruits and vegetables. Phytochemistry 62, 939-947. doi: 10.1016/S0031-9422(02) 00710-0

Caldana, C., Degenkolbe, T., Cuadros-Inostroza, A., Klie, S., Sulpice, R., Leisse, A., et al. (2011). High-density kinetic analysis of the metabolomic and transcriptomic response of Arabidopsis to eight environmental conditions. Plant J. 67, 869-884. doi: 10.1111/j.1365-313X.2011.04640.x

Chang, P., Gerhardt, K. E., Huang, X.-D., Yu, X.-M., Glick, B. R., Gerwing, P. D., et al. (2014). Plant growthpromoting bacteria facilitate the growth of barley and oats in saltimpacted soil: implications for phytoremediation of saline soils. Int. J. Phytoremediation 16, 1133-1147. doi: 10.1080/15226514.2013. 821447

Chauhan, A., Faziurrahman, Oakeshott, J. G., and Jain, R. K. (2008). Bacterial metabolism of polycyclic aromatic hydrocarbons: strategies for bioremediation. J. Ind. Microbiol. 48, 95-113. doi: 10.1007/s12088-008-0010-9

Chaves, M. M., and Oliveira, M. M. (2004). Mechanisms underlying plant resilience to waterdeficits: prospects for water-saving agriculture. J. Exp. Bot. 55, 23652384. doi: $10.1093 / \mathrm{jxb} / \mathrm{erh} 269$
Chen, J., Han, G., Shang, C., Li, J., Zhang, H., Liu, F., et al. (2015). Proteomic analyses reveal differences in cold acclimation mechanisms in freezing-tolerant and freezing-sensitive cultivars of alfalfa. Front. Plant Sci. 6:105. doi: 10.3389/ fpls.2015.00105

Chen, K., and Pachter, L. (2005). Bioinformatics for whole genome shotgun sequencing of microbial communities. PLoS Comput. Biol. 1, 106-112. doi: 10.1371/journal.pcbi.0010024

Chet, I., and Inbar, J. (1994). Biological control of fungal pathogens. Appl. Biochem. Biotechnol. 48, 37-43. doi: 10.1007/BF02825358

Chinnusamy, V., Schumaker, K., and Zhu, J. K. (2004). Molecular genetics perspectives on cross-talk and specifcity in abiotic stress signalling in plants. J. Exp. Bot. 55, 225-236. doi: 10.1093/jxb/erh005

Cho, S. M., Kang, B. R., Han, S. H., Anderson, A. J., Park, J. Y., Lee, Y. H., et al. (2008). 2R,3R-butanediol, a bacterial volatile produced by Pseudomonas chlororaphis $\mathrm{O6}$, is involved in induction of systemic tolerance to drought in Arabidopsis thaliana. Mol. Plant Microbe Interact. 21, 1067-1075. doi: 10.1094/ MPMI-21-8-1067

Contreras-Cornejo, H. A., Macías-Rodríguez, L., Cortés-Penagos, C., and LópezBucio, J. (2009). Trichoderma virens, a plant beneficial fungus, enhances biomass production and promotes lateral root growth through an auxindependent mechanism in Arabidopsis. Plant Physiol. 149, 1579-1592. doi: 10. 1104/pp.108.130369

Cordwell, S. J., Basseal, D. J., and Humphery-Smith, I. (1997). Proteome analysis of Spiroplasma melliferum (A56) and protein characterisation across species boundaries. Electrophoresis 18, 1335-1346. doi: 10.1002/elps.11501 80809

Cordwell, S. J., Wilkins, M. R., Cerpa-poljak, A., Gooley, A. A., Duncan, M., Williams, K. L., et al. (1995). Cross species identification of proteins separated by 2-dimensional gel-electrophoresis using matrix-assisted laser-desorption ionization time-of-flight mass-spectrometry and aminoacid-composition. Electrophoresis 16, 438-443. doi: 10.1002/elps.1150160171

Cramer, G. R., Urano, K., Delrot, S., Pezzotti, M., and Shinozaki, K. (2011). Effects of abiotic stress on plants: a systems biology perspective. BMC Plant Biol. 11:163. doi: 10.1186/1471-2229-11-163

Crane, T. A., Roncoli, C., and Hoogenboom, G. (2011). Adaptation to climate change and climate variability: the importance of understanding agriculture as performance. NJAS -Wag. J. Life Sci. 57, 179-185. doi: 10.1016/j.njas.2010. 11.002

Creus, C. M., Sueldo, R. J., and Barassi, C. A. (2004). Water relations and yield in Azospirillum-inoculated wheat exposed to drought in the field. Can. J. Bot. 82, 273-281. doi: 10.1139/b03-119

Cunrath, O., Gasser, V., Hoegy, F., Reimmann, C., Guillon, L., Schalk, I. J., et al. (2015). A cell biological view of the siderophore pyochelin iron uptake pathway in Pseudomonas aeruginosa. Environ. Microbiol. 17, 171-185. doi: 10.1111/ 1462-2920.12544

Curaba, J., Singh, M. B., and Bhalla, P. L. (2014). miRNAs in the crosstalk between phytohormone signalling pathways. J. Exp. Bot. 65, 1425-1438. doi: 10.1093/ jxb/eru002

Cushman, J. C., De Rocher, E. J., and Bohnert, H. J. (1990). “Gene expression during adaptation to salt stress," in Environmental Injury of Plants, ed. F. Kalterman (San Diego, CA: Academic Press), 173-203.

Daei, G., Ardekani, M. R., Rejali, F., Teimuri, S., and Miransari, M. (2009). Alleviation of salinity stress on wheat yield, yield components, and nutrient uptake using arbuscular mycorrhizal fungi under field conditions. J. Plant Physiol. 66, 617-625. doi: 10.1016/j.jplph.2008.09.013

Dardanelli, M. S., Fernández de Córdoba, F. J., Espuny, M. R., Rodríguez Carvajal, M. A., Soria Díaz, M. E., Gil Serrano, A. M., et al. (2008). Effect of Azospirillum brasilense coinoculated with Rhizobium on Phaseolus vulgaris flavonoids and Nod factor production under salt stress. Soil Biol. Biochem. 40, 2713-2721. doi: 10.1016/j.soilbio.2008.06.016

Davis, J. B., and Raymond, R. L. (1961). Oxidation of alkyl-substituted cyclic hydrocarbons by a nocardia during growth on n-alkanes. Appl. Microbiol. 9, 383-388.

de Castro, A. P., Sartori, A., Silva, M. R., Quirino, B. F., and Kruger, R. H. (2013). Combining "omics" strategies to analyze the biotechnological potential of complex microbial environments. Curr. Protein Pept. Sci. 14, 447-458.

de Lorenzo, L., Merchan, F., Laporte, P., Thompson, R., Clarke, J., Sousa, C., et al. (2009). A novel plant leucine-rich repeat receptor kinase regulates the 
response of Medicago truncatula roots to salt stress. Plant Cell 21, 668-680. doi: $10.1105 /$ tpc.108.059576

de Zelicourt, A., Al-Yousif, M., and Hirt, H. (2013). Rhizosphere microbes as essential partners for plant stress tolerance. Mol. Plant. 6, 242-245. doi: 10.1093/ $\mathrm{mp} / \mathrm{sst} 028$

Defez, R., Esposito, R., Angelini, C., and Bianco, C. (2016). Overproduction of indole-3-acetic acid in free-living rhizobia induces transcriptional changes resembling those occurring in nodule bacteroids. Mol. Plant Microbe Interact. 29, 484-495. doi: 10.1094/MPMI-01-16-0010-R

del Amor, F., and Cuadra-Crespo, P. (2012). Plant growth-promoting bacteria as a tool to improve salinity tolerance in sweet pepper. Funct. Plant Biol. 39, 82-90. doi: 10.1071/FP11173

Depuyd, S., and Hardtke, C. S. (2011). Hormone signalling crosstalk in plant growth regulation. Curr. Biol. 21, 365-373. doi: 10.1016/j.cub.2011.03.013

Diels, L., van der Lelie, N., and Bastiaens, L. (2002). New developments in treatment of heavy metal contaminated soils. Rev. Env. Sci. Biotechnol. 1, 75-82. doi: 10.1023/A:1015188708612

Dinneny, J. R., Long, T. A., Wang, J. Y., Jung, J. W., Mace, D., Pointer, S., et al. (2008). Cell identity mediates the response of Arabidopsis roots to abiotic stress. Science 320, 942-945. doi: 10.1126/science.1153795

Dourado, M. N., Camargo Neves, A. A., Santos, D. S., and Araújo, W. L. (2015). Biotechnological and agronomic potential of endophytic pink-pigmented methylotrophic Methylobacterium spp. Biomed. Res. Int. 2015:909016. doi: 10. $1155 / 2015 / 909016$

Egamberdiyeva, D., and Höflich, G. (2003). Influence of growth-promoting on the growth of wheat in different soils and temperatures. Soil Biol. Biochem. 35, 973-978. doi: 10.1016/S0038-0717(03)00158-5

El-Daim, I. A. A., Bejai, S., and Meijer, J. (2014). Improved heat stress tolerance of wheat seedlings by bacterial seed treatment. Plant Soil 379, 337-350. doi: 10.1007/s11104-014-2063-3

Emamverdian, A., Ding, Y., Mokhberdoran, F., and Xie, Y. (2015). Heavy metal stress and some mechanisms of plant defense response. Sci. World J. 2015:756120. doi: 10.1155/2015/756120

Eyers, L., George, I., Schuler, L., Stenuit, B., Agathos, S. N., and El, F. S. (2004). Environmental genomics: exploring the unmined richness of microbes to degrade xenobiotics. Appl. Microbiol. Biotechnol. 66, 123-130. doi: 10.1007/ s00253-004-1703-6

Farrar, K., Bryant, D., and Cope-Selby, N. (2014). Understanding and engineering beneficial plant-microbe interactions: plant growth promotion in energy crops. Plant Biotechnol. J. 12, 1193-1206. doi: 10.1111/pbi.12279

Ferret, C., Sterckeman, T., Cornu, J. Y., Gangloff, S., Schalk, I. J., and Geoffroy, V. A. (2014). Siderophore-promoted dissolution of smectite by fluorescent Pseudomonas. Environ. Microbiol. Rep. 6, 459-467. doi: 10.1111/1758-2229. 12146

Figueiredo, M. V. B., Burity, H. A., Martinez, C. R., and Chanway, C. P. (2008). Alleviation of drought stress in common bean (Phaseolus vulgaris L.) by coinoculation with Paenibacillus polymyxa and Rhizobium tropici. Appl. Soil Ecol. 40, 182-188. doi: 10.1016/j.apsoil.2008.04.005

Flowers, T. J., Galal, H. K., and Bromham, L. (2010). Evolution of halophytes: multiple origins of salt tolerance in land plants. Funct. Plant Biol. 37, 604-612. doi: 10.1007/s10142-011-0218-3

Foyer, C. H., and Noctor, G. (2005). Oxidant and antioxidant signalling in plants: a re-evaluation of the concept of oxidative stress in a physiological context. Plant Cell Environ. 28, 1056-1071. doi: 10.1111/j.1365-3040.2005.01327.x

Franken, P. (2012). The plant strengthening root endophyte Piriformospora indica: potential application and the biology behind. Appl. Microbiol. Biotechnol. 96, 1455-1464. doi: 10.1007/s00253-012-4506-1

Fugyeuredi, M. V. B., Vilhar, J. J., Burity, H. A., and de Franca, F. P. (1999). Alleviation of water stress effects in cowpea by Bradyrhizobium spp. inoculation. Pant Soil 207, 67-75.

Gaiero, J. R., McCall, C. A., Thompson, K. A., Day, N. J., Best, A. S., and Dunfield, K. E. (2013). Inside the root microbiome: bacterial root endophytes and plant growth promotion. Am. J. Bot. 100, 1738-1750. doi: 10.3732/ajb.1200572

Gao, P., Bai, X., Yang, L., Lv, D., Pan, X., Li, Y., et al. (2011). osa-MIR393: a salinity and alkaline stress-related microRNA gene. Mol. Biol. Rep. 38, 237-242. doi: 10.1007/s11033-010-0100-8

German, M. A., Burdman, S., Okon, Y., and Kigel, J. (2000). Effects of Azospirillum brasilense on root morphology of common bean (Phaseolus vulgaris L.) under different water regimes. Biol. Fertil. Soils 32, 259-264. doi: 10.1007/ s003740000245

Ghabooli, M., Khatabi, B., Ahmadi, F. S., Sepehri, M., Mirzaei, M., Amirkhani, A., et al. (2013). Proteomics study reveals the molecular mechanisms underlying water stress tolerance induced by Piriformospora indica in barley. J. Proteomics 94, 289-301. doi: 10.1016/j.jprot.2013.09.017

Gill, S. S., and Tuteja, N. (2010). Reactive oxygen species and antioxidant machinery in abiotic stress tolerance in crop plants. Plant Physiol. Biochem. 48, 909-930. doi: 10.1016/j.plaphy.2010.08.016

Gopalakrishnan, S., Sathya, A., Vijayabharathi, R., Varshney, R. K., Gowda, C. L., and Krishnamurthy, L. (2015). Plant growth promoting rhizobia: challenges and opportunities. 3Biotech 5, 355-377.

Grainger, C. M., and Rajcan, I. (2013). Characterization of the genetic changes in a multi-generational pedigree of an elite Canadian soybean cultivar. Theor. Appl. Genet. 127, 211-229. doi: 10.1007/s00122-013-2211-9

Gravel, V., Antoun, H., and Tweddell, R. J. (2007). Growth stimulation and fruit yield improvement of greenhouse tomato plants by inoculation with Pseudomonas putida or Trichoderma atroviride: possible role of indole acetic acid (IAA). Soil Biol. Biochem. 39, 1968-1977. doi: 10.1016/j.soilbio.2007. 02.015

Grayson, M. (2013). Agriculture and drought. Nature 501:S1. doi: 10.1038/501S1a

Grichko, V. P., and Glick, B. R. (2001). Amelioration of flooding stress by ACC deaminase containing plant growth promoting bacteria. Can. J. Microbiol. 47, 77-80.

Gupta, B., and Huang, B. (2014). Mechanism of salinity tolerance in plants: physiological, biochemical, and molecular characterization. Int. J. Genomics 2014:701596. doi: 10.1155/2014/701596

Hamdia, A. B. E., Shaddad, M. A. K., and Doaa, M. M. (2004). Mechanisms of salt tolerance and interactive effects of Azospirillum brasilense inoculation on maize cultivars grown under salt stress conditions. Plant Growth Regul. 44, 165-174. doi: 10.1023/B:GROW.0000049414.03099.9b

Handelsman, J., Tiedje, J., Alvarez-Cohen, L., Ashburner, M., Cann, I. K. O., Delong, E. F., et al. (2007). The New Science of Metagenomics: Revealing the Secrets of Our Microbial Planet. Washington, DC: National Academy of Science.

Hasegawa, P. M., Bressan, R. A., Zhu, J.-K., and Bohnert, H. J. (2000). Plant cellular and molecular responses to high salinity. Annu. Rev. Plant Biol. 51, 463-499. doi: 10.1146/annurev.arplant.51.1.463

Hayat, R., Ali, S., Amara, U., Khalid, R., and Ahmed, I. (2010). Soil beneficial bacteria and their role in plant growth promotion: a review. Ann. Microbiol. 60, 579-598. doi: 10.1007/s13213-010-0117-1

Heil, M., and Bostock, R. M. (2002). Induced systemic resistance (ISR) against pathogens in the context of induced plant defences. Ann. Bot. 89, 503-512. doi: $10.1093 / \mathrm{aob} / \mathrm{mcf076}$

Hey, S. J., Byrne, E., and Halford, N. G. (2010). The interface between metabolic and stress signalling. Ann. Bot. 105, 197-203. doi: 10.1093/aob/mcp285

Hilker, M., Schwachtje, J., Baier, M., Balazadeh, S., Bäurle, I., Geiselhardt, S., et al. (2015). Priming and memory of stress responses in organisms lacking a nervous system. Biol. Rev. 91, 1118-1133. doi: 10.1111/brv.12215

Hirel, B., Le Gouis, J., Ney, B., and Gallais, A. (2007). The challenge of improving nitrogenuse efficiency in crop plants: towards a more central role for genetic variability andquantitative genetics within integrated approaches. J. Exp. Bot. 58, 2369-2387. doi: 10.1093/jxb/erm097

Hollywood, K., Brison, R. D., and Goodacre, R. (2006). Metabolomics: current technologies and future trends. Proteomics 6, 4716-4723. doi: 10.1002/pmic. 200600106

Horvath, R. S. (1972). Microbial co-metabolism and the degradation of organic compounds in nature. Bacteriol. Rev. 36, 146-155.

Iba, K. (2002). Acclimative response to temperature stress in higher plants: approaches of gene engineering for temperature tolerance. Annu. Rev. Plant Biol. 53, 225-245. doi: 10.1146/annurev.arplant.53.100201.160729

Inceoglu, O. L., Al-Soud, W. A., Salles, J. F., Alexander, V. S., and Elsas, J. D. V. (2011). Comparative analysis of bacterial communities in a potato field as determined by pyrosequencing. PLoS ONE 6:e23321. doi: 10.1371/journal.pone. 0023321

Islam, F., Yasmeen, T., Ali, Q., Ali, S., Arif, M. S., Hussain, S., et al. (2014). Influence of Pseudomonas aeruginosa as PGPR on oxidative stress tolerance in wheat under Zn stress. Ecotoxicol. Environ. Saf. 104, 285-293. doi: 10.1016/j.ecoenv. 2014.03.008 
Iyer, N. J., Tang, Y., and Mahalingam, R. (2013). Physiological, biochemical and molecular responses to combination of drought and ozone in Medicago truncatula. Plant Cell Environ. 2013, 706-720. doi: 10.1111/pce. 12008

Jackson, M. B. (1991). "Regulation of water relationships in flooded plants by ABA from leaves, roots and xylem sap," in Abscisic Acid. Physiology and Biochemistry, eds W. J. Davis and H. G. Jones (Oxford: Bios Scientific), 217-226.

Jha, Y., Sablok, G., Subbarao, N., Sudhakar, R., Fazil, M. H. U. T., Subramanian, R. B., et al. (2014). Bacterial-induced expression of RAB18 protein in Orzya sativa salinity stress and insights into molecular interaction with GTP ligand. J. Mol. Recognit. 27, 521-527. doi: 10.1002/jmr.2371

Jia, X., Sun, C., Zuo, Y., Li, G., Li, G., Ren, L., et al. (2016). Integrating transcriptomics and metabolomics to characterise the response of Astragalus membranaceus Bge. var. mongolicus (Bge.) to progressive drought stress. BMC Genomics 17:188. doi: 10.1186/s12864-016-2554-0

Jia, X., Wang, W.-X., Ren, L., Chen, Q.-J., Mendu, V., Willcut, B., et al. (2009). Differential and dynamic regulation of miR398 in response to ABA and salt stress in Populus tremula and Arabidopsis thaliana. Plant Mol. Biol. 71, 51-59. doi: 10.1007/s11103-009-9508-8

Jiang, Q.-Y., Zhuo, F., Long, S.-H., Zhao, H.-D., Yang, D.-J., Ye, Z.-H., et al. (2016). Can arbuscular mycorrhizal fungi reduce Cd uptake and alleviate Cd toxicity of Lonicera japonica grown in Cd-added soils? Sci. Rep. 6:21805. doi: $10.1038 /$ srep 21805

Jiao, N., Herndl, G. J., Hansell, D. A., Benner, R., Kattner, G., Wilhelm, S. W., et al. (2010). Microbial production of recalcitrant dissolved organic matter: long-term carbon storage in the global ocean. Nat. Rev. Microbiol. 8, 593-599. doi: $10.1038 /$ nrmicro2386

Jin, J., Watt, M., and Mathesius, U. (2012). The auto regulation gene SUNN mediates changes in root organ formation in response to nitrogen through alteration of shoot-to-root auxin transport. Plant Physiol. 159, 489-500. doi: 10.1104/pp.112.194993

Jorge, T. F., Rodrigues, J. A., Caldana, C., Schmidt, R., van Dongen, J. T., Thomas-Oates, J., et al. (2015). Mass-spectrometry-based plant metabolomics: metabolite responses to abiotic stress. Mass Spectrom. Rev. 35, 620-649. doi: 10.1002/mas.21449

Kantar, M., Lucas, S. J., and Budak, H. (2011). miRNA expression patterns of Triticum dicoccoides in response to shock drought stress. Planta 233, 471-484. doi: 10.1007/s00425-010-1309-4

Kapardar, R. K., Ranjan, R., Grover, A., Puri, M., and Sharma, R. (2010). Identification and characterization of genes conferring salt tolerance to Escherichia coli from pond water metagenome. Bioresour. Technol. 101, 39173924. doi: 10.1016/j.biortech.2010.01.017

Kasotia, A., Varma, A., and Choudhary, D. K. (2015). Pseudomonas-mediated mitigation of salt stress and growth promotion in Glycine max. Agric. Res. 4, 31-41. doi: 10.1007/s40003-014-0139-1

Kasurinen, A., Biasi, C., Holopainen, T., Rousi, M., Maenpaa, M., and Oksanen, E. (2012). Interactive effects of elevated ozone and temperature on carbon allocation of silver birch (Betula pendula) genotypes in an open-air field exposure. Tree Physiol. 32, 737-751. doi: 10.1093/treephys/ tps005

Kaushal, M., and Wani, S. P. (2016). Plant-growth-promoting rhizobacteria: drought stress alleviators to ameliorate crop production in drylands. Ann. Microbiol. 66, 35-42. doi: 10.1007/s13213-015-1112-3

Kaya, C., Ashraf, M., Sonmez, O., Aydemir, S., Tuna, A. L., and Cullu, M. A. (2009). The influence of arbuscular mycorrhizal colonisation on key growth parameters and fruit yield of pepper plants grown at high salinity. Sci. Hortic. 121, 1-6. doi: 10.1016/j.scienta.2009.01.001

Kertesz, M. A., Leisinger, T., and Cook, A. M. (1993). Proteins induced by sulfate limitation in Escherichia coli, Pseudomonas putida, or Staphylococcus aureus. J. Bacteriol. 175, 1187-1190. doi: 10.1128/jb.175.4.1187-1190. 1993

Ketchum, R. E., Rithner, C. D., Qiu, D., Kim, Y. S., Williams, R. M., and Croteau, R. B. (2003). Taxus metabolomics: methyl jasmonate preferentially induces production of taxoids oxygenated at C-13 in Taxus $\mathrm{x}$ media cell cultures. Phytochemistry 62, 901-909. doi: 10.1016/S0031-9422(02) 00711-2

Khan, A., Sirajuddin, Zhao, X. Q., Javed, M. T., Khan, K. S., Bano, A., et al. (2016). Bacillus pumilus enhances tolerance in rice (Oryza sativa
L.) to combined stresses of $\mathrm{NaCl}$ and high boron due to limited uptake of $\mathrm{Na}+$. Environ. Exp. Bot. 124, 120-129. doi: 10.1016/j.envexpbot.2015. 12.011

Khan, M. A., Gemenet, D. C., and Villordon, A. (2016). Root system architecture and abiotic stress tolerance: current knowledge in root and tuber crops. Front. Plant Sci. 7:1584. doi: 10.3389/fpls.2016.01584

Kim, S. I., Choi, J. S., and Kahng, H. Y. (2007). A proteomics strategy for the analysis of bacterial biodegradation pathways. OMICS 11, 280-294. doi: 10. 1089/omi.2007.0019

Kissoudis, C., van de Wiel, C., Visser, R. G. F., and van der Linden, G. (2014). Enhancing crop resilience to combined abiotic and biotic stress through the dissection of physiological and molecular crosstalk. Front. Plant Sci. 5:207. doi: $10.3389 /$ fpls.2014.00207

Koini, M. A., Alvey, L., Allen, T., Tilley, C. A., Harberd, N. P., Whitelam, G. C., et al. (2009). High temperature-mediated adaptations in plant architecture require the bHLH transcription factor PIF4. Curr. Biol. 19, 408-413. doi: 10.1016/j.cub. 2009.01.046

Kosova, K., Vitamvas, P., Urban, M. O., Klima, M., Roy, A., and Prasil, I. T. (2015). Biological networks underlying abiotic stress tolerance in temperate crops- a proteomic perspective. Int. J. Mol. Sci. 16, 20913-20942. doi: 10.3390/ ijms160920913

Koussevitzky, S., Suzuki, N., Huntington, S., Armijo, L., Sha, W., Cortes, D., et al. (2008). Ascorbate peroxidase 1 plays a key role in the response of Arabidopsis thaliana to stress combination. J. Biol. Chem. 283, 34197-34203. doi: 10.1074/ jbc.M806337200

Kubicek, C. P., Herrera-Estrella, A., Seidl-Seiboth, V., Martinez, D. A., Druzhinina, I. S., Thon, M., et al. (2011). Comparative genome sequence analysis underscores mycoparasitism as the ancestral life style of Trichoderma. Genome Biol. 12:R40. doi: 10.1186/gb-2011-12-4-r40

Kumari, S., Vaishnav, A., Jain, S., Varma, A., and Choudhary, D. K. (2015). Bacterial-mediated induction of systemic tolerance to salinity with expression of stress alleviating enzymes in soybean (Glycine max L. Merrill). J. Plant Growth Regul. 34, 558-573. doi: 10.1007/s00344-0159490-0

Li, J. L., Cui, J., and Cheng, D. Y. (2015). Computational identification and characterization of conserved miRNAs and their target genes in beet (Beta vulgaris) Genet. Mol. Res. 14, 9103-9108. doi: 10.4238/2015. August.7.19

Li, Q., Zhao, P., Li, J., Zhang, C., Wang, L., and Ren, Z. (2014). Genomewide analysis of the WD-repeat protein family in cucumber and Arabidopsis. Mol. Genet. Genomics 289, 103-124. doi: 10.1007/s00438-0130789-x

Li, Y. F., Zheng, Y., Addo-Quaye, C., Zhang, L., Saini, A., Jagadeeswaran, G., et al. (2010). Transcriptome-wide identification of microRNA targets in rice. Plant J. 62, 742-759. doi: 10.1111/j.1365-313X.2010.04187.x

Li, Z., Setsuko, W., Fischer, B. B., and Niyogi, K. K. (2009). Sensing and responding to excess light. Annu. Rev. Plant Biol. 60, 239-260. doi: 10.1146/annurev. arplant.58.032806.103844

Licausi, F., Ohme-Takagi, M., and Perata, P. (2013). APETALA2/Ethylene Responsive Factor (AP2/ERF) transcription factors: mediators of stress responses and developmental programs. New Phytol. 199, 639-649. doi: 10. $1111 /$ nph.12291

Liljeqvist, M., Ossandon, F. J., Gonzalez, C., Rajan, S., Stell, A., Valdes, J., et al. (2015). Metagenomic analysis reveals adaptations to a cold-adapted lifestyle in a low-temperature acid mine drainage stream. FEMS Microbiol. Ecol. 91:fiv011. doi: 10.1093/femsec/fiv011

Lim, J. H., and Kim, S. D. (2013). Induction of drought stress resistance by multifunctional PGPR Bacillus licheniformis K11 in pepper. Plant Pathol. J. 29, 201-208. doi: 10.5423/PPJ.SI.02.2013.0021

Lima, J. C., Arenhart, R. A., Margis-Pinheiro, M., and Margis, R. (2011). Aluminum triggers broad changes in microRNA expression in rice roots. Genet. Mol. Res. 10, 2817-2832. doi: 10.4238/2011.November.10.4

Liu, Z., Li, Y., Cao, H., and Ren, D. (2015). Comparative phospho-proteomics analysis of salt-responsive phosphoproteins regulated by the MKK9-MPK6 cascade in Arabidopsis. Plant Sci. 241, 138-150. doi: 10.1016/j.plantsci.2015. 10.005

Luan, Y., Cui, J., Zhai, J., Li, J., Han, L., and Meng, J. (2015). High-throughput sequencing reveals differential expression of miRNAs in tomato inoculated 
with Phytophthora infestans. Planta 241, 1405-1416. doi: 10.1007/s00425-0152267-7

Lupi, C. G., Colangelo, T., and Mason, C. A. (1995). Two-dimensional gel electrophoresis analysis of the response of Pseudomonas putida KT2442 to 2-Chlorophenol. Appl. Environ. Microbiol. 61, 2863-2872.

Ma, J. F., Mitani, N., Nagao, S., Konishi, S., Tamai, K., Iwashita, T., et al. (2004). Characterization of the Silicon uptake system and molecular mapping of the Silicon transporter gene in rice. Plant Physiol. 136, 3284-3289. doi: 10.1104/pp. 104.047365

Ma, Y., Rajkumar, M., Luo, Y., and Freitas, H. (2013). Phytoextraction of heavy metal polluted soils using Sedum plumbizincicola inoculated with metal mobilizing Phyllobacterium myrsinacearum RC6b. Chemosphere 93, 1386-1392. doi: 10.1016/j.chemosphere.2013.06.077

Madhaiyan, M., Poonguzhali, S., and Sa, T. (2007). Metal tolerating methylotrophic bacteria reduces nickel and cadmium toxicity and promotes plant growth of tomato (Lycopersicon esculentum L.). Chemosphere 69, 220-228. doi: 10.1016/j. chemosphere.2007.04.017

Manavalan, L. P., Guttikonda, S. K., Tran, L. S. P., and Nguyen, H. T. (2009). Physiological and molecular approaches to improve drought resistance in soybean. Plant Cell Physiol. 50, 1260-1276. doi: 10.1093/pcp/ pcp082

Martínez-Cortés, T., Pomar, F., Merino, F., and Novo-Uzal, E. (2014). A proteomic approach to Physcomitrella patens rhizoid exudates. J. Plant Physiol. 171, 1671-1678. doi: 10.1016/j.jplph.2014.08.004

Marulanda, A., Azcón, R., Chaumont, F., Ruiz-Lozano, J. M., and Aroca, R. (2010). Regulation of plasma membrane aquaporins by inoculation with a Bacillus megaterium strain in maize (Zea mays L.) plants under unstressed and salt-stressed conditions. Planta 232, 533-543. doi: 10.1007/s00425-0101196-8

Marulanda, A., Porcel, R., Barea, J. M., and Azcon, R. (2007). Drought tolerance and antioxidant activities in lavender plants colonized by native drought tolerant or drought sensitive Glomus species. Microb. Ecol. 54, 543-552. doi: 10.1007/s00248-007-9237-y

Massad, T. J., Dyer, L. A., and Vega, C. G. (2012). Cost of defense and a test of the carbon-nutrient balanceand growth-differentation balance hypotheses for two co-occurring classes of plant defense. PLOS ONE 7:7554. doi: 10.1371/journal. pone. 0047554

Mathew, D. C., Ho, Y.-N., Gicana, R. G., Mathew, G. M., Chien, M.-C., and Huang, C.-C. (2015). A rhizosphere-associated symbiont, Photobacterium spp. strain MELD1, and its targeted synergistic activity for phytoprotection against mercury. PLOS ONE 10:e0121178. doi: 10.1371/journal.pone. 0121178

Matilla, M. A., Ramos, J. L., Bakker, P. A., Doornbos, R., Badri, D. V., Vivanco, J. M., et al. (2010). Pseudomonas putida KT2440 causes induced systemic resistance and changes in Arabidopsis root exudation. Environ. Microbiol. Rep. 2, 381-388. doi: 10.1111/j.1758-2229.2009.00091.x

Matysik, J., Alia, A., Bhalu, B., and Mohanty, P. (2002). Molecular mechanisms of quenching of reactive oxygen species by proline under stress in plants. Curr. Sci. $82,525-532$.

Mayak, S., Tirosh, T., and Glick, B. R. (2004). Plant growth-promoting bacteria confer resistance in tomato plants to salt stress. Plant Physiol. Biochem. 42, 565-572. doi: 10.1016/j.plaphy.2004.05.009

McCue, K. F., and Hanson, A. D. (1990). Salt-inducible betaine aldehyde dehydrogenase from sugar beet: cDNA cloning and expression. Trends Biotechnol. 8, 358-362. doi: 10.1016/0167-7799(90)90225-M

Meena, K. K., Kumar, M., Kalyuzhnaya, M. G., Yandigeri, M. S., Singh, D. P., Saxena, A. K., et al. (2012). Epiphytic pink-pigmented methylotrophic bacteria enhance germination and seedling growth of wheat (Triticum aestivum) by producing phytohormone. Antonie Van Leeuwenhoek 101, 777-786. doi: 10. 1007/s10482-011-9692-9

Meng, C., Zeleznik, O. A., Thallinger, G. G., Kuster, B., Gholami, A. M., and Culhane, A. C. (2016). Dimension reduction techniques for the integrative analysis of multi-omics data. Brief. Bioinform. 17, 628-641. doi: 10.1093/bib/ bbv108

Micallef, S. A., Channer, S., Shiaris, M. P., and Colón-Carmona, A. (2009). Plant age and genotype impact the progression of bacterial community succession in the Arabidopsis rhizosphere. Plant Signal. Behav. 4, 777-780. doi: 10.1093/jxb/ erp053
Mickelbart, M. V., Paul, M., Hasegawa, P. M., and Bailey-Serres, J. (2015). Genetic mechanisms of abiotic stress tolerance that translate to crop yield stability. Nat. Rev. Genet. 16, 237-251. doi: 10.1038/nrg3901

Mishra, B. K., Meena, K. K., Dubey, P. N., Aishwath, O. P., Kant, K., Sorty, A. M., et al. (2016). Influence on yield and quality of fennel (Foeniculum vulgare Mill.) grown under semi-arid saline soil, due to application of native phosphate solubilizing rhizobacterial isolates. Ecol. Eng. 97, 327-333. doi: 10. 1016/j.ecoleng.2016.10.034

Mittler, R. (2006). Abiotic stress, the field environment and stress combination. Trends Plant Sci. 11, 15-19. doi: 10.1016/j.tplants.2005.11.002

Mittler, R., and Blumwald, E. (2010). Genetic engineering for modern agriculture: challenges and perspectives. Annu. Rev. Plant Biol. 61, 443-462. doi: 10.1146/ annurev-arplant-042809-112116

Moliterni, V. M. C., Paris, R., Onofri, C., Orrù, L., Cattivelli, L., Pacifico, D., et al. (2015). Early transcriptional changes in Beta vulgaris in response to low temperature. Planta 242, 187-201. doi: 10.1007/s00425-0152299-Z

Morrow, K. J. Jr. (2010). Mass spec central to metabolomics. Gen. Eng. Biotechnol. News 30, 1-3.

Munns, R., and Tester, M. (2008). Mechanisms of salinity tolerance. Annu. Rev. Plant Biol. 59, 651-681. doi: 10.1146/annurev.arplant.59.032607.092911

Nadeem, S. M., Ahmad, M., Zahir, Z. A., Javaid, A., and Ashraf, M. (2014). The role of mycorrhizae and plant growth promoting rhizobacteria (PGPR) in improving crop productivity under stressful environments. Biotechnol. Adv. 32, 429-448. doi: 10.1016/j.biotechadv.2013.12.005

Nadeem, S. M., Zahir, Z. A., Naveed, M., and Arshad, M. (2007). Preliminary investigations on inducing salt tolerance in maize through inoculation with rhizobacteria containing ACC deaminase activity. Can. J. Microbiol. 53, 11411149. doi: 10.1139/W07-081

Nakashima, K., and Yamaguchi-Shinozaki, K. (2006). Regulons involved in osmotic stress-responsive and cold stress-responsive gene expression in plants. Physiol. Plant. 126, 62-71. doi: 10.1111/j.1399-3054.2005.00592.x

Nakayama, H., Yoshida, K., and Ono, H. (2000). Ectoine, the compatible solute of Halomonas elongata, confers hyperosmotic tolerance in cultured tobacco cells. Plant Physiol. 122, 1239-1247. doi: 10.1104/pp.122.4.1239

Natsch, A., Keel, C., Pfirter, H. A., Haas, D., and Défago, G. (1994). Contribution of the global regulator gene gacA to persistence and dissemination of Pseudomonas fluorescens biocontrol strain CHA0 introduced into soil microcosms. Appl. Environ. Microbiol. 60, 2553-2560.

Naveed, M., Hussain, M. B., Zahir, Z. A., Mitter, B., and Sessitsch, A. (2014a). Drought stress amelioration in wheat through inoculation with Burkholderia phytofirmans strain PsJN. Plant Growth Regul. 73, 121-131. doi: 10.1007/ s10725-013-9874-8

Naveed, M., Mitter, B., Reichenauer, T. G., Wieczorek, K., and Sessitsch, A. (2014b). Increased drought stress resilience of maize through endophytic colonization by Burkholderia phytofirmans PsJN and Enterobacter sp FD17. Environ. Exp. Bot. 97, 30-39. doi: 10.1016/j.envexpbot.2013.09.014

Naya, L., Ladrera, R., Ramos, J., González, E. M., Arrese-Igor, C., Minchin, F. R., et al. (2007). The response of carbon metabolism and antioxidant defenses of alfalfa nodules to drought stress and to the subsequent recovery of plants. Plant Physiol. 144, 1104-1114. doi: 10.1104/pp.107.099648

Neeraja, C. N., Maghirang-Rodriguez, R., Pamplona, A., Heuer, S., Collard, B. C. Y., Septiningsih, E. M., et al. (2007). A marker-assisted backcross approach for developing submergence-tolerant rice cultivars. Theor. Appl. Genet. 115, 767776. doi: 10.1007/s00122-007-0607-0

Ngumbi, E., and Kloepper, J. (2014). Bacterial-mediated drought tolerance: current and future prospects. Appl. Soil Ecol. 105, 109-125. doi: 10.1016/j.apsoil.2016. 04.009

Nguyen, D., Rieu, I., Mariani, C., and van Dam, N. M. (2016). How plants handle multiple stresses: hormonal interactions underlying responses to abiotic stress and insect herbivory. Plant Mol. Biol. 91, 727-740. doi: 10.1007/s11103-0160481-8

Nikolic, B., Schwab, H., and Sessitsch, A. (2011). Metagenomic analysis of the 1-aminocyclopropane-1-carboxylate deaminase gene (acdS) operon of an uncultured bacterial endophyte colonizing Solanum tuberosum L. Arch. Microbial. 193, 665-676. doi: 10.1007/s00203-011-0703-z

Noack, S., and Wiechert, W. (2014). Quantitative metabolomics: a phantom? Trends Biotechnol. 5, 238-244. doi: 10.1016/j.tibtech.2014.03.006 
Olah, B., Briere, C., Becard, G., Denarie, J., and Gough, C. (2005). Nod factors and a diffusible factor from arbuscular mycorrhizal fungi stimulate lateral root formation in Medicago truncatula via the DMI1/DMI2 signalling pathway. Plant J. 44, 195-207. doi: 10.1111/j.1365-313X.2005.02522.x

Oldroyd, G. E. D. (2013). Speak, friend, and enter: signalling systems that promote beneficial symbiotic associations in plants. Nat. Rev. Microbiol. 11, 252-263. doi: $10.1038 /$ nrmicro2990

Oldroyd, G. E. D., and Downie, J. A. (2008). Coordinating nodule morphogenesis with rhizobial infection in legumes. Annu. Rev. Plant Biol. 59, 519-546. doi: 10.1146/annurev.arplant.59.032607.092839

Oliveira, C. A., Alves, V. M. C., Marriel, I. E., Gomes, E. A., Scotti, M. R., Carneiro, N. P., et al. (2009). Phosphate solubilizing microorganisms isolated from rhizosphere of maize cultivated in an oxisol of the Brazilian Cerrado biome. Soil Biol. Biochem. 41, 1782-1787. doi: 10.1016/j.soilbio.2008. 01.012

Omar, M. N. A., Osman, M. E. H., Kasim, W. A., and Abd El-Daim, I. A. (2009). Improvement of salt tolerance mechanisms of barley cultivated under salt stress using Azospirillum brasiliense. Tasks Veg. Sci. 44, 133-147. doi: 10.1007/978-14020-9065-3_15

Onaga, G., and Wydra, K. (2016). "Advances in plant tolerance to abiotic stresses," in Plant Genomics, ed. I. Y. Abdurakhmonov (Rijeka: InTech). doi: 10.5772/ 64350

Ortiz, N., Armadaa, E., Duque, E., Roldánc, A., and Azcóna, R. (2015). Contribution of arbuscular mycorrhizal fungi and/or bacteria to enhancing plant drought tolerance under natural soil conditions: effectiveness of autochthonous or allochthonous strains. J. Plant Physiol. 174, 87-96. doi: 10. 1016/j.jplph.2014.08.019

Osakabe, Y., Arinaga, N., Umezawa, T., Katsura, S., Nagamachi, K., Tanaka, H., et al. (2013). Osmotic stress responses and plant growth controlled by potassium transporters in Arabidopsis. Plant Cell 25, 609-624. doi: 10.1105/tpc.112.105700

Osakabe, Y., Osakabe, K., Shinozaki, K., and Tran, L.-S. P. (2014). Response of plants to water stress. Front. Plant Sci. 5:86. doi: 10.3389/fpls.2014. 00086

Padgham, J. (2009). Agricultural Development Under a Changing Climate: Opportunities and Challenges for Adaptation. Washington, DC: Agriculture and Rural Development \& Environmental Departments, The World Bank.

Palaniyandi, S. A., Damodharan, K., Yang, S. H., and Suh, J. W. (2014). Streptomyces sp. strain PGPA39 alleviates salt stress and promotes growth of 'Micro Tom' tomato plants. J. Appl. Microbiol. 117, 766-773. doi: 10.1111/jam. 12563

Pandey, V., Ansari, M. W., Tula, S., Yadav, S., Sahoo, R. K., Shukla, N., et al. (2016). Dose-dependent response of Trichoderma harzianum in improving drought tolerance in rice genotypes. Planta 243, 1251-1264. doi: 10.1007/s00425-0162482-x

Panlada, T., Pongdet, P., Aphakorn, L., Rujirek, N.-N., Nantakorn, B., and Neung, T. (2013). Alleviation of the effect of environmental stresses using co-inoculation of mungbean by Bradyrhizobium and rhizobacteria containing stress-induced ACC deaminase enzyme. Soil Sci. Plant Nut. 59, 559-571. doi: 10.1080/00380768.2013.804391

Pareek, A., Sopory, S. K., Bohnert, H. K., and Govindjee. (eds) (2010). Abiotic Stress Adaptation in Plants: Physiolgical, Molecular and Genomic Foundation. Dordrecht: Springer, 526.

Peiffer, J. A., Spor, A., Koren, O., Jin, Z., Tringe, S. G., Dangl, J. L., et al. (2013). Diversity and heritability of the maize rhizosphere microbiome under field conditions. Proc. Natl. Acad. Sci. U.S.A. 110, 6548-6553. doi: 10.1073/pnas. 1302837110

Pereira, S. I., and Castro, P. M. (2014). Diversity and characterization of culturable bacterial endophytes from Zea mays and their potential as plant growthpromoting agents in metal-degraded soils. Environ. Sci. Pollut. Res. Int. 24, 14110-14123. doi: 10.1007/s11356-014-3309-6

Perez-Lopez, U., Miranda-Apodaca, J., Munoz-Rueda, A., and MenaPetite, A. (2013). Lettuce production and antioxidant capacity are differentially modified by salt stress and light intensity under ambient and elevated CO2. J. Plant Physiol. 170, 1517-1525. doi: 10.1016/j.jplph.2013. 06.004

Pinedo, I., Ledger, T., Greve, M., and Poupin, M. J. (2015). Burkholderia phytofirmans PsJN induces long-term metabolic and transcriptional changes involved in Arabidopsis thaliana salt tolerance. Front. Plant Sci. 6:466. doi: 10.3389/flps.2015.00466

Pishchik, V. N., Vorobyev, N. I., Chernyaeva, I. I., Timofeeva, S. V., Kozhemyakov, A. P., Alexeev, Y. V., et al. (2002). Experimental and mathematical simulation of plant growth promoting rhizobacteria and plant interaction under cadmium stress. Plant Soil 243, 173-186. doi: 10.1023/A:1019941 525758

Plociniczak, T., Sinkkonen, A., Romantschuk, M., and Piotrowska-seget, Z. (2013). Characterization of Enterobacter intermedius MH8b and its use for the enhancement of heavy metal uptake by Sinapsis alba L. Appl. Soil Ecol. 63, 1-7. doi: 10.1016/j.apsoil.2012.09.009

Porcel, R., and Ruiz-Lozano, J. M. (2004). Arbuscular mycorrhizal influence on leaf water potential, solute accumulation and oxidative stress in soybean plants subjected to drought stress. J. Exp. Bot. 55, 1743-1750. doi: 10.1093/jxb/ erh188

Prasch, C. M., and Sonnewald, U. (2013). Simultaneous application of heat, drought, and virus to Arabidopsis plants reveals significant shifts in signaling networks. Plant Physiol. 162, 1849-1866. doi: 10.1104/pp.113.221044

Purdy, S. J., Maddison, A. L., Jones, L. E., Webster, R. J., Andralojc, J., Donnison, I., et al. (2013). Characterization of chilling-shock responses in four genotypes of Miscanthus reveals the superior tolerance of $M$. x giganteus compared with M. sinensis and M. sacchariflorus. Ann. Bot. 111, 999-1013. doi: 10.1093/aob/ mct059

Qadir, M., Quillérou, E., Nangia, V., Murtaza, G., Singh, M., Thomas, R. J., et al. (2014). Economics of salt-induced land degradation and restoration. Nat. Resour. Forum. 38, 282-295. doi: 10.1111/1477-8947.12054

Qin, F., Shinozaki, K., and Yamaguchi-Shinozaki, K. (2011). Achievements and challenges in understanding plant abiotic stress responses and tolerance. Plant Cell Physiol. 52, 1569-1582. doi: 10.1093/pcp/pcr106

Rabie, G. H. (2005). Influence of arbuscular mycorrhizal fungi and kinetin on the response of mungbean plants to irrigation with seawater. Mycorrhiza 15, 225-230. doi: 10.1007/s00572-004-0345-y

Raes, J., and Bork, P. (2008). Molecular eco-systems biology: towards an understanding of community function. Nat. Rev. Microbiol. 6, 693-699. doi: 10.1038/nrmicro1935

Raymond, R. L., Jamison, V. W., and Hudson, J. O. (1967). Microbial hydrocarbon co-oxidation. I. oxidation of mono- and dicyclic hydrocarbons by soil isolates of the genus Nocardia. Appl. Microbiol. 15, 857-865.

Reardon, K. F., and Kim, K. H. (2002). Two-dimensional electrophoresis analysis of protein production during growth of Pseudomonas putida F1 on toluene, phenol, and their mixture. Electrophoresis 23, 2233-2241. doi: 10.1002/15222683(200207)23:14<2233::AID-ELPS2233<3.0.CO;2-B

Remans, R., Ramaekers, L., Shelkens, S., Hernandez, G., Garcia, A., Reyes, G. L., et al. (2008). Effect of Rhizobium, Azospirillum co-inoculation on nitrogen fixation and yield of two contrasting Phaseolus vulgaris L. genotypes cultivated across different environments in Cuba. Plant Soil 312, 25-37. doi: 10.1007/ s11104-008-9606-4

Riadh, K., Wided, M., Hans-Werner, K., and Chedly, A. (2010). Responses of halophytes to environmental stresses with special emphasis to salinity. Adv. Bot. Res. 53, 117-145. doi: 10.1016/S0065-2296(10)53004-0

Rivas-Ubach, A., Sardans, J., Perez-Trujillo, M., Estiarte, M., and Penuelas, J. (2012). Strong relationship between elemental stoichiometry and metabolome in plants. Proc. Natl. Acad. Sci. U.S.A. 109, 4181-4186. doi: 10.1073/pnas. 1116092109

Rivero, R. M., Mestre, T. C., Mittler, R., Rubio, F., Garcia-Sanchez, F., and Martinez, V. (2013). The combined effect of salinity and heat reveals a specific physiological, biochemical and molecular response in tomato plants. Plant Cell Environ. 37, 1059-1073. doi: 10.1111/pce.12199

Rizhsky, L., Liang, H., and Mittler, R. (2002). The combined effect of drought stress and heat shock on gene expression in tobacco. Plant Physiol. 130, 1143-1151. doi: 10.1104/pp.006858

Rizhsky, L., Liang, H. J., Shuman, J., Shulaev, V., Davletova, S., and Mittler, R. (2004). When defense pathways collide. The response of Arabidopsis to a combination of drought and heat stress. Plant Physiol. 134, 1683-1696. doi: 10.1104/pp.103.033431

Robin, A., Mougel, C., Siblot, S., Vansuyt, G., Mazurier, S., and Lemanceau, P. (2006). Effect of ferritin overexpression in tobacco on the structure of bacterial 
and pseudomonad communities associated with the roots. FEMS Microbiol. Ecol. 58, 492-502. doi: 10.1111/j.1574-6941.2006.00174.x

Rorison, I. H. (1986). The response of plants to acid soils. Experintia 42:357-362. doi: 10.1007/BF02118616

Ruan, C. J., da Silva, J. A. T., Mopper, S., Qin, P., and Lutts, S. (2010). Halophyte improvement for a salinized world. Crit. Rev. Plant Sci. 29, 329-359. doi: 10. 1080/07352689.2010.524517

Sahoo, R. K., Ansari, M. W., Dangar, T. K., Mohanty, S., and Tuteja, N. (2014a). Phenotypic and molecular characterisation of efficient nitrogen-fixing Azotobacter strains from rice fields for crop improvement. Protoplasma 251, 511-523. doi: 10.1007/s00709-013-0547-2

Sahoo, R. K., Ansari, M. W., Pradhan, M., Dangar, T. K., Mohanty, S., and Tuteja, N. (2014b). A novel Azotobacter vinellandii (SRIAz3) functions in salinity stress tolerance in rice. Plant Sig. Behav. 9:e29377. doi: 10.4161/psb. 29377

Sandhya, V., Ali, S. K. Z., Minakshi, G., Reddy, G., and Venkateswarlu, B. (2009). Alleviation of drought stress effects in sunflower seedlings by the exopolysaccharides producing Pseudomonas putida strain GAP-P45. Biol. Fertil. Soils 46, 17-26. doi: 10.1007/s00374-009-0401-z

Sannazzaro, A. I., Ruiz, O. A., Alberto, E. O., and Menéndez, A. B. (2006). Alleviation of salt stress in Lotus glaber by Glomus intraradices. Plant Soil 285, 279-287. doi: 10.1007/s11104-006-9015-5

Santos, R. D., Patel, M., Cuadros, J., and Martins, Z. (2016). Influence of mineralogy on the preservation of amino acids under simulated Mars conditions. Icarus 277, 342-353. doi: 10.1016/j.icarus.2016.05.029

Sauer, K., Camper, A. K., Ehrlich, G. D., Costerton, J. W., and Davies, D. G. (2002). Pseudomonas aeruginosa displays multiple phenotypes during development as a biofilm. J. Bacteriol. 184, 1140-1154. doi: 10.1128/jb.184.4.1140-1154.2002

Sauer, K., Cullen, M. C., Rickard, A. H., Zeef, L. A., Davies, D. G., and Gilbert, P. (2004). Characterization of nutrient-induced dispersion in Pseudomonas aeruginosa PAO1 biofilm. J. Bacteriol. 186, 7312-7326.

Schenk, P. M., Carvalhais, L. C., and Kazan, K. (2012). Unraveling plant-microbe interactions: can multi-species transcriptomics help? Trends Biotechnol. 30, 177-184. doi: 10.1016/j.tibtech.2011.11.002

Schulze, W. X. (2005). Protein analysis in dissolved organic matter: what proteins from organic debris, soil leachate and surface water can tell us-a perspective. Biogeosciences 2, 75-86. doi: 10.5194/bg-2-75-2005

Schweder, T., Markert, S., and Hecker, M. (2008). Proteomics of marine bacteria. Electrophoresis 29, 2603-2616. doi: 10.1002/elps.200800009

Sehrawat, A., Gupta, R., and Deswal, R. (2013). Nitric oxide-cold stress signalling cross-talk, evolution of a novel regulatory mechanism. Proteomics 13, 18161835. doi: $10.1002 /$ pmic. 201200445

Sen, S., and Chandrasekhar, C. N. (2014). Effect of PGPR on growth promotion of rice (Oryza sativa L.) under salt stress. Asian J. Plant Sci. Res. 4, 62-67.

Septiningsih, E. M., Pamplona, A. M., Sanchez, D. L., Neeraja, C. N., Vergara, G. V., Heuer, S., et al. (2009). Development of submergence-tolerant rice cultivars: the Sub1 locus and beyond. Ann. Bot. 103, 151-160. doi: 10.1093/aob/mcn206

Sessitsch, A., Hardoim, P., Döring, J., Weilharter, A., Krause, A., Woyke, T., et al. (2012). Functional characteristics of an endophyte community colonizing roots as revealed by metagenomic analysis. Mol. Plant Microbe Interact. 25, 28-36. doi: 10.1094/MPMI-08-11-0204

Shao, H. B., Chu, L. Y., Jaleel, C. A., and Zhao, C. X. (2008). Water-deficit stressInduced anatomical changes in higher plants. Crit. Rev. Biol. 331, 215-225. doi: $10.1016 /$ j.crvi.2008.01.002

Sharifi, M., Ghorbanli, M., and Ebrahimzadeh, H. (2007). Improved growth of salinity-stressed soybean after inoculation with salt pre-treated mycorrhizal fungi. J. Plant Physiol. 164, 1144-1151. doi: 10.1016/j.jplph.2006.06.016

Sharma, A., Shankhdhar, D., and Shankhdhar, S. C. (2013). Enhancing grain iron content of rice by the application of plant growth promoting rhizobacteria. Plant Soil Environ. 59, 89-94.

Shevchenko, A., Sunyaev, S., Loboda, A., Schevchenko, A., Bork, P., Ens, W., et al. (2001). Charting the proteomes of organisms with unsequenced genomes by MALDI-quadrupole time of flight mass spectrometry and BLAST homology searching. Anal. Chem. 73, 1917-1926. doi: 10.1021/ac0013709

Silva, E. N., Ribeiro, R. V., Ferreira-Silva, S. L., Viégas, R. A., and Silveira, J. A. G. (2010). Comparative effects of salinity and water stress on photosynthesis, water relations and growth of Jatropha curcas plants. J. Arid. Environ. 74, 1130-1137. doi: 10.1016/j.jaridenv.2010.05.036
Silva-Sanchez, C., Li, H., and Chen, S. (2015). Recent advances and challenges in plant phosphoproteomics. Proteomics 15, 1127-1141. doi: 10.1002/pmic. 201400410

Simontacchi, M., Galatro, A., Ramos-Artuso, F., and Santa-Maria, G. E. (2015). Plant survival in a changing environment : the role of nitric oxide in plant responses to abiotic stress. Front. Plant Sci. 6:977. doi: 10.3389/fpls.2015. 00977

Singh, D. P., Prabha, R., Yandigeri, M. S., and Arora, D. K. (2011). Cyanobacteriamediated phenylpropanoids and phytohormones in rice (Oryza sativa) enhance plant growth and stress tolerance. Antonie Van Leeuwenhoek 100, 557-568. doi: 10.1007/s10482-011-9611-0

Singh, R., Singh, P., and Sharma, R. (2014). Microorganism as a tool of bioremediation technology for cleaning environment: A review. Proc. Int. Acad. Ecol. Environ. Sci. 4, 1-6.

Singh, S. (2014). A review on possible elicitor molecules of cyanobacteria: their role in improving plant growth and providing tolerance against biotic or abiotic stress. J. Appl. Microbiol. 117, 1221-1244. doi: 10.1111/jam.12612

Sonah, H., Deshmukh, R. K., Sharma, A., Singh, V. P., Gupta, D. K., Gacche, R. N., et al. (2011). Genome-wide distribution and organization of microsatellites in plants: an insight into marker development in Brachypodium. PLoS ONE 6:21298. doi: 10.1371/journal.pone.0021298

Sorty, A. M., Meena, K. K., Choudhary, K., Bitla, U. M., Minhas, P. S., and Krishnani, K. K. (2016). Effect of plant growth promoting bacteria associated with halophytic weed (Psoralea corylifolia L.) on germination and seedling growth of wheat under saline conditions. Appl. Biochem. Biotechnol. 180, 872-882. doi: 10.1007/s12010-016-2139-z

Sorty, A. M., and Shaikh, N. R. (2015). Novel co-enrichment method for isolation of magnetotactic bacteria. J. Basic Microbiol. 55, 520-526. doi: 10.1002/jobm. 201400457

Souza, R. D., Ambrosini, A., and Passaglia, L. M. P. (2015). Plant growth-promoting bacteria as inoculants in agricultural soils. Genet. Mol. Biol. 38, 401-419. doi: $10.1590 /$ S1415-475738420150053

Spoel, S. H., and Dong, X. (2008). Making sense of hormone crosstalk during plant immune response. Cell Host Microbe. 3, 348-351. doi: 10.1016/j.chom.2008. 05.009

Srivastava, G., Kumar, S., Dubey, G., Mishra, V., and Prasad, S. M. (2012). Nickel and ultraviolet-B stresses induce differential growth and photosynthetic responses in Pisum sativum L. seedlings. Biol. Trace Elem. Res. 49, 86-96. doi: 10.1007/s12011-012-9406-9

Srivastava, S., Verma, P. C., Chaudhry, V., Singh, N., Abhilash, P. C., Kumar, K. V., et al. (2013). Influence of inoculation of arsenic-resistant Staphylococcus arlettae on growth and arsenic uptake in Brassica juncea (L.) Czern. Var. R-46. J. Hazard. Mater. 262, 1039-1047. doi: 10.1016/j.jhazmat.2012.08.019

Suarez, C., Cardinale, M., Ratering, S., Steffens, D., Jung, S., Montoya, A. M. Z., et al. (2015). Plant growth-promoting effects of Hartmannibacter diazotrophicus on summer barley (Hordeum vulgare L.) under salt stress. Appl. Soil Ecol. 95, 23-30. doi: 10.1016/j.apsoil.2015.04.017

Sun, C., Johnson, J., Cai, D., Sherameti, I., Oelmüeller, R., and Lou, B. (2010). Piriformosporaindica confers drought tolerance in Chinese cabbage leaves by stimulating antioxidant enzymes, the expression of drought-related genes and the plastid-localized CAS protein. J. Plant. Physiol. 167, 1009-1017. doi: 10. 1016/j.jplph.2010.02.013

Sunkar, R., Kapoor, A., and Zhu, J. K. (2006). Posttranscriptional Induction of Two $\mathrm{Cu} / \mathrm{Zn}$ superoxide dismutase genes in Arabidopsis is mediated by downregulation of miR398 and important for oxidative stress tolerance. Plant Cell 18, 2051-2065. doi: 10.1105/tpc.106.041673

Swaine, E. K., Swaine, M. D., and Killham, K. (2007). Effects of drought on isolates of Bradyrhizobium elkanii cultured from Albizia adianthifolia seedlings on different provenances. Agroforest. Syst. 69, 135-145. doi: 10.1007/s10457-0069025-6

Swarbrick, P. J., Schulze-Lefert, P., and Scholes, J. D. (2006). Metabolic consequences of susceptibility and resistance in barley leaves challenged with powdery mildew. Plant Cell Environ. 29, 1061-1076. doi: 10.1111/j.1365-3040. 2005.01472.x

Takanashi, K., Sasaki, T., Kan, T., Saida, Y., Sugiyama, A., Yamamoto, Y., et al. (2016). A dicarboxylate transporter, LjALMT4, mainly expressed in nodules of Lotus japonicus. Mol. Plant Microbe Interact. 29, 584-592. doi: 10.1094/MPMI04-16-0071-R 
Tani, A., Takai, Y., Suzukawa, I., Akita, M., Murase, H., and Kimbara, K. (2012). Practical application of methanol-mediated mutualistic symbiosis between Methylobacterium species and a roof greening moss, Racomitrium japonicum. PLoS ONE 7:e33800. doi: 10.1371/journal.pone.0033800

Tapias, D. R., Galvan, A. M., Diaz, S. P., Obando, M., Rivera, D., and Bonilla, R. (2012). Effect of inoculation with plant growth-promoting bacteria (PGPB) on amelioration of saline stress in maize (Zea mays). Appl. Soil Ecol. 61, 264-272. doi: 10.1016/j.apsoil.2012.01.006

Thomashow, M. F. (2010). Molecular basis of plant cold acclimation: insights gained from studying the CBF cold response pathway. Plant Physiol. 154, 571-577. doi: 10.1104/pp.110.161794

Timmusk, S., El-Daim, I. A. A., Copolovici, L., Tanilas, T., Kännaste, A., Behers, L., et al. (2014). Drought-tolerance of wheat improved by rhizosphere bacteria from harsh environments: enhanced biomass production and reduced emissions of stress volatiles. PLOS ONE 9:e96086. doi: 10.1371/journal.pone. 0096086

Timmusk, S., and Wagner, E. G. H. (1999). The plant growth-promoting rhizobacterium Paenibacillus polymyxa induces changes in Arabidopsis thaliana gene expression, a possible connection between biotic and abiotic stress responses. Mol. Plant Microbe Interact. 12, 951-959. doi: 10.1094/MPMI.1999. 12.11.951

Tiwari, S., Singh, P., Tiwari, R., Meena, K. K., Yandigeri, M., Singh, D. P., et al. (2011). Salt-tolerant rhizobacteria-mediated induced tolerance in wheat (Triticum aestivum) and chemical diversity in rhizosphere enhance plant growth. Biol. Fertil. Soils 47, 907-916. doi: 10.1007/s00374-011-0598-5

Todaka, D., Nakashima, K., Shinozaki, K., and Yamaguchi-Shinozaki, K. (2012). Toward understanding transcriptional regulatory networks in abiotic stress responses and tolerance in rice. Rice J. 5, 1-9. doi: 10.1186/19398433-5-6

Tomar, R. S. S., Deshmukh, R. K., Naik, K., and Tomar, S. M. S. (2014). Development of chloroplast-specific microsatellite markers for molecular characterization of alloplasmic lines and phylogenetic analysis in wheat. Plant Breed. 133, 12-18. doi: 10.1111/pbr.12116

Toojinda, T., Siangliw, M., Tragroonrung, S., and Vanavichit, A. (2003). Molecular genetics of submergence tolerance in rice: QTL analysis of key traits. Ann. Bot. 91, 243-253. doi: 10.1093/aob/mcf072

Trindade, I., Capitao, C., Dalmay, T., Fevereiro, M. P., and Santos, D. M. (2010). miR398 and miR408 are up-regulated in response to water deficit in Medicago truncatula. Planta 231, 705-716. doi: 10.1007/s00425-009-1078-0

Tringe, S. G., von Mering, C., Kobayashi, A., Salamov, A. A., Chen, K., Chang, H. W., et al. (2005). Comparative metagenomics of microbial communities. Science 308, 554-557. doi: 10.1126/science.1107851

Tucci, M., Ruocco, M., De Masi, L., De Palma, M., and Lorito, M. (2011). The beneficial effect of Trichoderma spp. on tomato is modulated by the plant genotype. Mol. Plant. Pathol. 12, 341-354. doi: 10.1111/j.1364-3703.2010. 00674.x

Turner, T. R., James, E. K., and Poole, P. S. (2013a). The plant microbiome. Genome Biol. 14:209. doi: 10.1186/gb-2013-14-6-209

Turner, T. R., Ramakrishnan, K., Walshaw, J., Heavens, D., Alston, M., Swarbreck, D., et al. (2013b). Comparative metatranscriptomics reveals kingdom level changes in the rhizosphere microbiome of plants. ISME J. 7, 2248-2258. doi: 10.1038/ismej.2013.119

Vaishnav, A., Kumari, S., Jain, S., Verma, A., Tuteja, N., and Choudhary, D. K. (2016). PGPR-mediated expression of salt tolerance gene in soybean through volatiles under sodium nitroprusside. J. Basic Microbiol. 56, 1274-1288. doi: 10.1002/jobm.201600188

Vansuyt, G., Robin, A., Briat, J. F., Curie, C., and Lemanceau, P. (2007). Iron acquisition from Fe-pyoverdine by Arabidopsis thaliana. Mol. Plant Microbe Interact. 20, 441-447. doi: 10.1094/MPMI-20-4-0441

Vardharajula, S., Ali, S. Z., Grover, M., Reddy, G., and Bandi, V. (2011). Droughttolerant plant growth promoting Bacillus spp.: effect on growth, osmolytes, and antioxidant status of maize under drought stress. J. Plant Int. 6, 1-14.

VerBerkmoes, N. C., Shah, M. B., Lankford, P. K., Pelletier, D. A., Strader, M. B., Tabb, D. L., et al. (2006). Determination and comparison of the baseline proteomes of the versatile microbe Rhodopseudomonas palustris under its major metabolic states. J. Proteome Res. 5, 287-298. doi: 10.1021/pr0503230

Vinale, F., Sivasithamparam, K., Ghisalberti, E. L., Marra, R., Barbetti, M. J., Li, H., et al. (2008). A novel role for Trichoderma secondary metabolites in the interactions with plants. Physiol. Mol. Plant Pathol. 72, 80-86. doi: 10.1016/j. pmpp.2008.05.005

Viterbo, A., Landau, U., Kim, S., Chernin, L., and Chet, I. (2010). Characterization of ACC deaminase from the biocontrol and plant growth-promoting agent Trichoderma asperellum T203. FEMS Microbiol. Lett. 305, 42-48. doi: 10.1111/ j.1574-6968.2010.01910.x

Voesenek, L. A. C. J., and Pierik, R. (2008). Plant stress profiles. Science 320, 880-881. doi: 10.1126/science. 1158720

Wahid, A., Gelani, S., Ashraf, M., and Foolad, M. R. (2007). Heat tolerance in plants: an overview. Environ. Exp. Bot. 61, 199-223. doi: 10.1016/j.envexpbot. 2007.05.011

Wang, C., Yang, W., Wang, C., Gu, C., Niu, D., Liu, H., et al. (2012). Induction of drought tolerance in cucumber plants by a consortium of three plant growthpromoting rhizobacterium strains. PLoS ONE 7:e52565. doi: 10.1371/journal. pone. 0052565

Wang, L. J., and Li, S. L. (2006). Salicylic acid-induced heat or cold tolerance in relation to $\mathrm{Ca} 2+$ homeostasis and antioxidant systems in young grape plants. Plant Sci. 170, 685-694. doi: 10.1016/j.plantsci.2005.09.005

Wang, L. Y., Xie, Y. S., Cui, Y. Y., Xu, J., He, W., Chen, H. G., et al. (2015). Conjunctively screening of biocontrol agents (BCAs) against fusarium root rot and fusarium head blight caused by Fusarium graminearum. Microbiol. Res. 177, 34-42. doi: 10.1016/j.micres.2015.05.005

Wang, W., Vinocur, B., and Altman, A. (2003). Plant responses to drought, salinity andextreme temperatures: towards genetic engineering for stress tolerance. Planta 218, 1-14. doi: 10.1007/s00425-003-1105-5

Wang, Y., Hu, B., Du, S., Gao, S., Chen, X., and Chen, D. (2016). Proteomic analyses reveal the mechanism of Dunaliella salina Ds-26-16 gene enhancing salt tolerance in Escherichia coli. PLoS ONE 11:e0153640. doi: 10.1371/journal. pone. 0153640

Wani, S. H., Kumar, V., Shriram, V., and Sah, S. K. (2016). Phytohormones and their metabolic engineering for abiotic stress tolerance in crop plants. Crop J. 4, 162-176. doi: 10.1016/j.cj.2016.01.010

Williams, P. M., and de Mallorca, M. S. (1982). Abscisic acid and gibberellin-like substances in roots and root nodules of Glycine max. Plant Soil 65, 19-26. doi: 10.1007/BF02376799

Xu, J., Lan, H., Fang, H., Huang, X., Zhang, H., and Huang, J. (2015). Quantitative proteomic analysis of the rice (Oryza sativa L.) salt response. PLoS ONE 10:e0120978. doi: 10.1371/journal.pone.0120978

Xu, X., Zhou, G., and Shimizu, H. (2010). Plant responses to drought and rewatering. Plant Signal. Behav. 5, 649-654. doi: 10.4161/psb.5.6. 11398

Xu, Y., Lu, Y., Xie, C., Gao, S., Wan, J., and Prasanna, B. M. (2012). Wholegenome strategies for marker-assisted plant breeding. Mol. Breed. 29, 833-854. doi: 10.1007/s11032-012-9724-9

Xu, Z., Jiang, Y., Jia, B., and Zhou, G. (2016). Elevated-CO2 response of stomata and its dependence on environmental factors. Front. Plant Sci. 7:657. doi: 10. 3389/fpls.2016.00657

Xu, Z., Jiang, Y., and Zhou, G. (2015). Response and adaptation of photosynthesis, respiration, and antioxidant systems to elevated CO2 with environmental stress in plants. Front. Plant Sci. 6:701. doi: 10.3389/fpls.2015.00701

Xu, Z., Shimizu, H., Ito, S., Yagasaki, Y., Zou, C., Zhou, G., et al. (2014). Effects of elevated $\mathrm{CO} 2$, warming and precipitation change on plant growth, photosynthesis and peroxidation in dominant species from North China grassland. Planta 239, 421-435. doi: 10.1007/s00425-013-1987-9

$\mathrm{Xu}$, Z. Z., and Zhou, G. S. (2006). Combined effects of water stress and high temperature on photosynthesis, nitrogen metabolism and lipid peroxidation of a perennial grass Leymus chinensis. Planta 224, 1080-1090. doi: 10.1007/ s00425-006-0281-5

Yao, D., Zhang, X., Zhao, X., Liu, C., Wang, C., Zhang, Z., et al. (2011). Transcriptome analysis reveals salt-stressregulated biological processes and key pathways in roots of cotton (Gossypium hirsutum L.). Genomics 98, 47-55. doi: 10.1016/j.ygeno.2011.04.007

Yao, L. X., Wu, Z. S., Zheng, Y. Y., Kaleem, I., and Li, C. (2010). Growth promotion and protection against salt stress by Pseudomonas putida Rs-198 on cotton. Eur. J. Soil Biol. 46, 49-54. doi: 10.1016/j.ejsobi.2009.11.002

Yim, W., Seshadri, S., Kim, K., Lee, G., and Sa, T. (2013). Ethylene emission and PR protein synthesis in ACC deaminase producing Methylobacterium spp. inoculated tomato plants (Lycopersicon esculentum Mill.) challenged with 
Ralstonia solanacearum under greenhouse conditions. Plant Physiol. Biochem. 67, 95-104. doi: 10.1016/j.plaphy.2013.03.002

Yin, R., Han, K., Heller, W., Albert, A., Dobrev, P. I., Zažímalová, E., et al. (2014). Kaempferol 3-O-rhamnoside-7-O-rhamnoside is an endogenous flavonol inhibitor of polar auxin transport in Arabidopsis shoots. New Phytol. 201, 466-475. doi: 10.1111/nph.12558

Yolcu, S., Ozdemir, F., Güler, A., and Bor, M. (2016). Histone acetylation influences the transcriptional activation of POX in Beta vulgaris L. and Beta maritima L. under salt stress. Plant Physiol. Biochem. 100, 37-46. doi: 10.1016/j.plaphy.2015. 12.019

Yuan, H., Zhang, T., Liu, X., Deng, M., Zhang, W., Wen, Z., et al. (2015). Sumoylation of CCAAT/ enhancer-binding protein a is implicated in hematopoietic stem/progenitor cell development through regulating runxl in zebrafish. Sci. Rep. 5:9011. doi: 10.1038/srep09011

Zabala, M. D., Bennett, M. H., Truman, W. H., and Grant, M. R. (2009). Antagonism between salicylic and abscisic acid reflects early host-pathogen conflict and moulds plant defence responses. Plant J. 59, 375-386. doi: 10.1111/ j.1365-313X.2009.03875.X

Zhang, H., Kim, M. S., Sun, Y., Dowd, S. E., Shi, H., and Paré, P. W. (2008). Soil bacteria confer plant salt tolerance by tissue-specific regulation of the sodium transporter HKT1. Mol. Plant Microbe Interact. 21, 737-744. doi: 10.1094/ MPMI-21-6-0737
Zhang, X., Zou, Z., Gong, P., Zhang, J., Ziaf, K., Li, X., et al. (2011). Over-expression of microRNA169 confers enhanced drought tolerance to tomato. Biotechnol. Lett. 33, 403-409. doi: 10.1007/s10529-010-0436-0

Zhang, X. S., and Cheng, H. P. (2006). Identification of Sinorhizobium meliloti early symbiotic genes by use of a positive functional screen. Appl. Environ. Microbiol. 72, 2738-2748. doi: 10.1128/AEM.72.4.2738-2748.2006

Zhao, M. G., Chen, L., Zhang, L. L., and Zhang, W. H. (2009). Nitric reductasedependent nitric oxide production is involved in cold acclimation and freezing tolerance in Arabidopsis. Plant Physiol. 151, 755-767. doi: 10.1104/pp.109. 140996

Conflict of Interest Statement: The authors declare that the research was conducted in the absence of any commercial or financial relationships that could be construed as a potential conflict of interest.

Copyright (c) 2017 Meena, Sorty, Bitla, Choudhary, Gupta, Pareek, Singh, Prabha, Sahu, Gupta, Singh, Krishanani and Minhas. This is an open-access article distributed under the terms of the Creative Commons Attribution License (CC BY). The use, distribution or reproduction in other forums is permitted, provided the original author(s) or licensor are credited and that the original publication in this journal is cited, in accordance with accepted academic practice. No use, distribution or reproduction is permitted which does not comply with these terms. 